
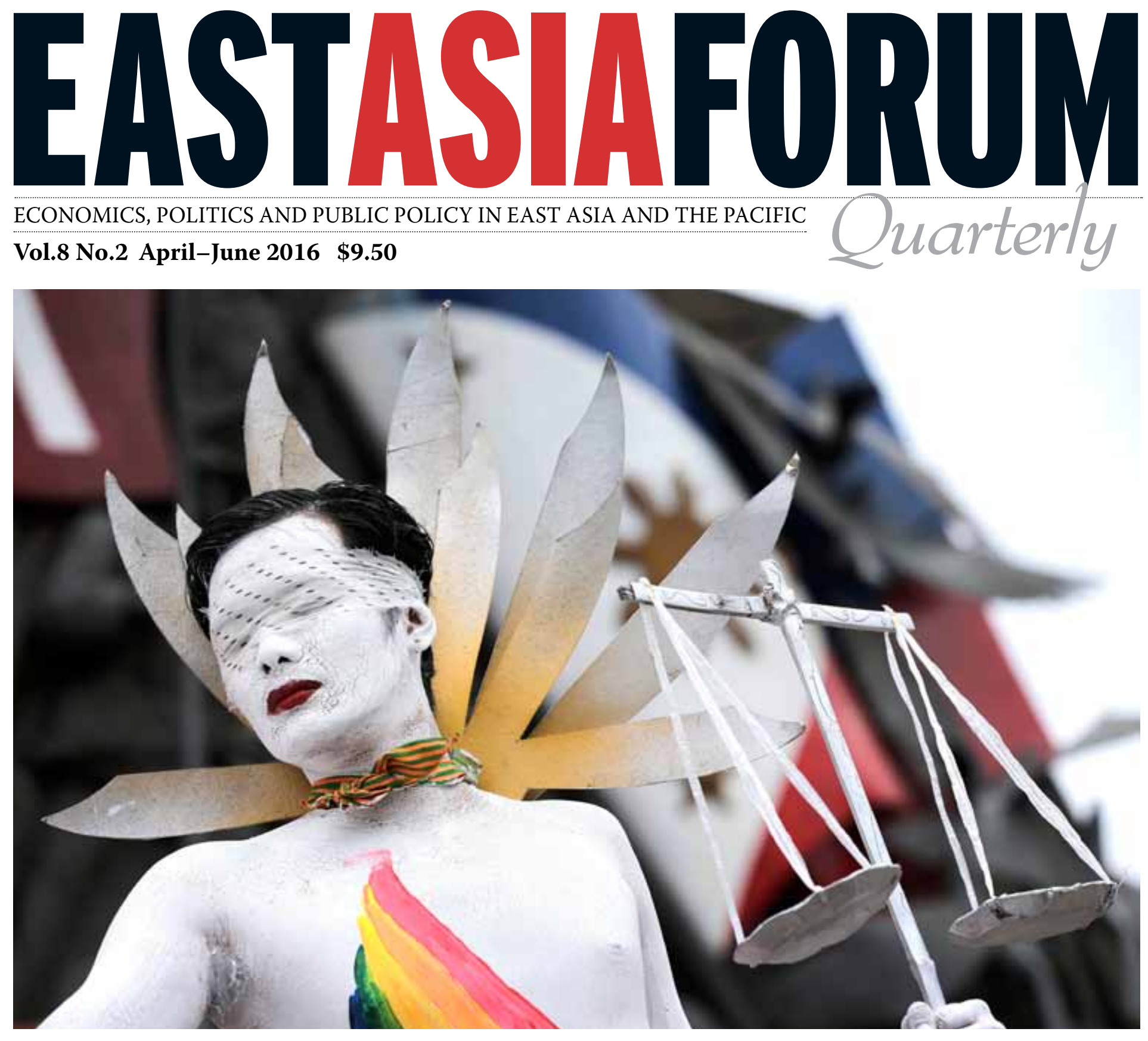

\title{
Gender and sexuality
}

Sharyn Graham Davies Indonesia's anti-LGBT panic

Bronwen Dalton and Kyungja Jung Femininity in North Korea

Vera Mackie Closing the gender gap in Japan

Katharine H. S. Moon Women and politics in East Asia ... and more ASIAN REVIEW - Robert A. Manning and James J. Przystup: What might a new Asian order look like? 


\section{EASTASIAFORUM \\ Quarterly \\ ISSN 1837-5081 (print) \\ ISSN 1837-509X (online)}

\section{From the editors' desk}

The dynamism seen in contemporary Asia has a deep gender dimension.

Rapid economic changes have fundamentally challenged the traditional division of labour of women working in the private, family domain and men in the public sphere of commerce and politics. Greater participation by women in politics has reshaped agendas for social change.

The seemingly fixed images of masculinity and femininity are in flux, accelerated by the commercialisation of popular culture across the region. Although the LGBT community is still struggling to gain wider acceptance, it has made strides that have challenged the hegemonic status of heteronormativity.

In the area of body politics, where the state and religious groups still exert enormous influence, women have been resisting or sometimes appropriating the debate to put forward their own agenda. The search for employment or new life opportunities has driven thousands of women to migrate, legally or illegally, within Asia as brides, labourers, traders or sex workers.

In the midst of these transformations, there has been encouraging evidence of legal changes that recognise the rights of women, exemplified in the abolition of various patriarchal laws, such as South Korea's familyhead system, or by the enactment of equal opportunity laws or the lifting of bans on women in the military. Yet old discriminatory norms and practices persist and are further complicated by regional political and economic developments.

This issue of East Asia Forum Quarterly brings together prominent scholars of gender studies from various countries and disciplines to explore the diversity and complexity of issues of gender and sexuality in contemporary Asia. The essays touch on major developments that have caused shifts in gender relations. They illustrate the tensions between structural violence against women and women's own agency in coping with male-dominant social arrangements.

The main message is that gender politics do not merely reflect societal shifts. They drive the political, economic and cultural changes that are transforming the 21st century Asian region.

The Asian Review section looks at the future of Indian federalism and the question of a new regional order.

\section{Hyaeweol Choi and Tessa Morris-Suzuki}

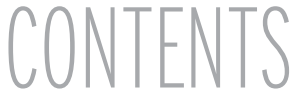

\section{GENG SONG}

Changing masculinities in East Asian pop culture

\section{JU HUI JUDY HAN}

The politics of homophobia in South

Korea

\section{SHARYN GRAHAM DAVIES}

Indonesia's anti-LGBT panic

\section{KATHRYN ROBINSON}

Religion, gender and the state in

Indonesia

\section{CHEN TINGTING}

Domestic violence: why legal change alone is not enough

\section{M. GOVINDA RAO}

ASIAN REVIEW: Making federalism work for India

19 ROBERT A. MANNING AND

JAMES J. PRZYSTUP

ASIAN REVIEW: What might a new

Asian order look like?

\section{CAROLINE NORMA}

East Asia's pornography trade and abuse of human rights

\section{HYUN MEE KIM}

The 'strangest others' find a place at home

\section{SABINE FRÜHSTÜCK}

Japan's military battles its own male-dominated culture

\section{BRONWEN DALTON AND KYUNGJA JUNG}

Women's image transformed: femininity in North Korea

\section{VERA MACKIE}

Closing the gender gap in Japan

34 KATHARINE H. S. MOON

Women and politics in East Asia

COVER: A Filipino protester from a gay and lesbian activist group mocks 'Lady Justice' at a rally in Manila which called for the resignation of then Philippines President Benigno Aquino. PICTURE: DENNIS M. SABANGAN / EPA / AAP. 


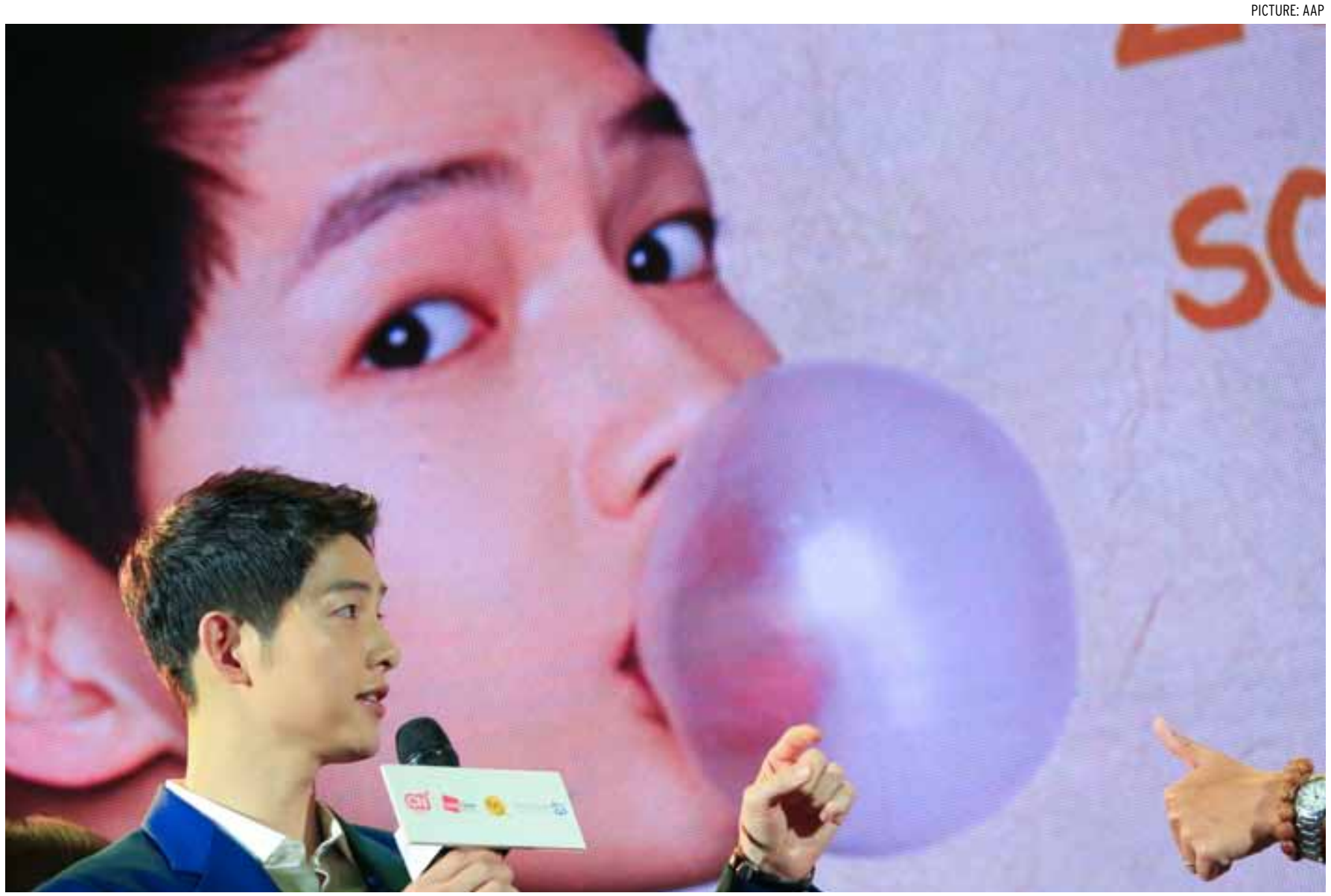

The fans' favourite: South Korean actor Song Joong-ki, epitome of the current trend towards Pan-East Asian soft masculinity.

\section{Changing masculinities in East Asian pop culture}

\section{GENG SONG}

D ESCENDANTS of the Sun, a South Korean TV drama featuring a romance between a soldier and a surgeon in a fictional war-torn nation, is reigniting K-drama fever across Asia. In China alone, where the program is simultaneously broadcast online, it has drawn more than 2.4 billion views on video-streaming website iQIYI since it began airing in late February.

Its fandom is mostly composed of young women who are fixated with the handsome male protagonist played by Song Joong-ki. It is reported that a jealous husband in China one night drunkenly stormed into a photography studio and demanded that the shop owner take pictures to 'make him look like Song.'

The cult of male beauty associated with Descendants of the Sun is reminiscent of a recent trend that has been termed 'Pan-East Asian soft masculinity' - male images that are exceptionally feminine to Western eyes. These types of images are mainly produced and circulated by the 'Korean Wave' and Japanese anime, comics and games (ACG) culture. It is well received by youth across most of East Asia, and presents a significant response to the globally hegemonic masculine ideal based on the image of the transnational businessman.

Some claim that the success of South Korean and Japanese pop culture lies in attempts to make it mugukjeok or 'culturally odourless' by downplaying their national specificity. 
EASTASIAFORUM EDITORIAL STAFF

\section{Issue Editors}

Hyaeweol Choi, Director, Korea Institute, and ANU-Korea Foundation Professor of Korean Studies, College of Asia and the Pacific, ANU.

Tessa Morris-Suzuki, Professor of Japanese History, College of Asia and the Pacific, ANU.

\section{Series Editors}

Peter Drysdale, Head, East Asia Forum and East Asian Bureau of Economic Research at the Crawford School of Public Policy, ANU.

Shiro Armstrong, Director, AustraliaJapan Research Centre and Executive Director, EAF and EABER, Crawford School, ANU.

\section{Editorial Staff}

Coordination: Sam Hardwick.

Editing: Alison Darby, Patrick Deegan, Catherine Yen, Liam Gammon, Rosa Bishop, Sam Hardwick, Michael Wijnen, ANU.

Editorial Advisers: Peter Fuller, Max Suich.

Production: Peter Fuller, Words \& Pics. Original design: Peter Schofield.

Email Peter.Drysdale@anu.edu.au, Shiro.Armstrong@anu.edu.au.

The views expressed are those of the individual authors and do not represent the views of the Crawford School, ANU, EABER, EAF, or the institutions to which the authors are attached.

\section{ANU PRESS}

Published by ANU Press The Australian National University Canberra ACT 0200, Australia Email: anupress@anu.edu.au Web: http://press.anu.edu.au
But for many others its popularity can be largely explained by its representations of Pan-East Asian soft masculinity.

Pan-East Asian soft masculinity has its roots in the Confucian tradition of scholar masculinity shared by many East Asian cultures, such as the wen (literary attainment) masculinity in China or seonbi (scholar-officials) masculinity in Korean history. The talented scholar is physically weak, delicate and handsome, with androgynous beauty. He is desirable to women by dint of his knowledge and literary gifts.

At the same time, the current popularity of these images of masculine beauty also reflects the influence of the metrosexual trend from the West. This indicates that masculinity has become increasingly pluralistic and hybridised in a rapidly globalising East Asia.

One conspicuous example of the transnational flow of male images in East Asia is the spread of otaku culture. With the international spread of anime and manga, the term otak $u$ has entered other cultures and generated new expressions. In Chinese, the vogue word zhainan (the Chinese pronunciation of the Japanese kanji for otaku) refers to a socially awkward young man who secludes himself in his home all day, indulging in computer games, anime and geek culture.

Despite the Japanese term's association with antisocial behaviour, more and more young men in Chinese cities identify themselves as zhainan and the term has come to indicate a desirable form of masculinity. There are Web essays on how to woo a zhainan and love stories featuring high school students and their zhainan teacher. The zhai lifestyle has even become a trend among urban youth.

\section{the current popularity}

\section{of these images of}

masculine beauty also

reflects the influence of

the metrosexual trend

from the West

The popularity of zhainan in China may be explained by the discourse in premodern Chinese literature on the 'purity' of men who have obsessions.

Compared with zhainan, the word meng bears an even more direct link with Japanese pop culture, being the Chinese pronunciation of the Japanese character moe. Moe, which originally meant 'budding' or 'burning, now refers to a particular kind of 'adorable' or 'cute' preadolescent girl in ACG culture. Like otaku, the word has undergone transformations in meaning and usage during its migration to China.

In the Chinese context, meng, which can be used as a noun, adjective or even a verb, has become a trendy word among young people, particularly in cyberspace. It can be used to describe a wide of range of things: from children's expressions to President Xi Jinping's new hairstyle. Notably, it is increasingly used to describe loveliness in men. When a man is referred to as meng, there is a (positive) implication of femininity. The popularity of zhainan and meng in China, on the whole, represents a growing cultural convergence among East Asian countries.

The 'softness' of Pan-East Asian masculinity also lies in its more 
sensitive and caring attitude toward women. The 'Herbivore Man' (sōshoku danshi) in Japan and South Korea, and 'Warm Man' (nuan nan) in China are all in line with this type of sensitive new guy.

The term Herbivore Man and its counterpart, 'Carnivorous Woman', were first coined by the Japanese author Maki Fukasawa and became known through Megumi Ushikubo's popular book The Herbivorous Ladylike Men: A Change in Japan. This new type of man is arguably a rebellion against the ideal salaryman masculinity of postwar Japan. They are less ambitious and are 'harmless' for women because they always display an understanding of women and their feelings.

The 2013 Chinese hit film, Finding Mr Right, centres on the idealised Warm Man. The male protagonist played by Wu Xiubo used to be a renowned doctor in Beijing but gives up his career in order to look after his teenage daughter in the United States. In China, he also epitomises the ideal sensitive man who harbours warm emotions for women.

'Tough' masculine images are coterminous with 'soft' ones in East Asian popular culture. One example of the former is heroic men in China's anti-Japanese TV dramas, a popular subgenre of TV program in China. This government-sponsored and market-oriented 'consumerist nationalism' represents a happy marriage between the state's agenda and popular social desires in Chinese television.

In these dramas, patriotic Chinese masculinity is portrayed against its Other, the 'Japanese devils.' The characterisation of Japanese officers and soldiers reflects stereotypes that are deeply rooted in the collective memory and imagination of generations of Chinese, gained from popular media if not from actual experience. For instance, the cold-blooded Japanese commander predictably commits hara-kiri when ultimately faced with defeat. The Japanese officer regularly slaps his subordinates in fits of anger, with baka (Japanese for 'fool' or 'idiot') always on his lips. He also regularly mistreats women, while his submissive wife bows deeply to welcome him home every evening.

It is against these images of Japanese men that an idealised Chinese manhood is portrayed and eulogised. EAFQ

Geng Song is Associate Professor at the University of Hong Kong.

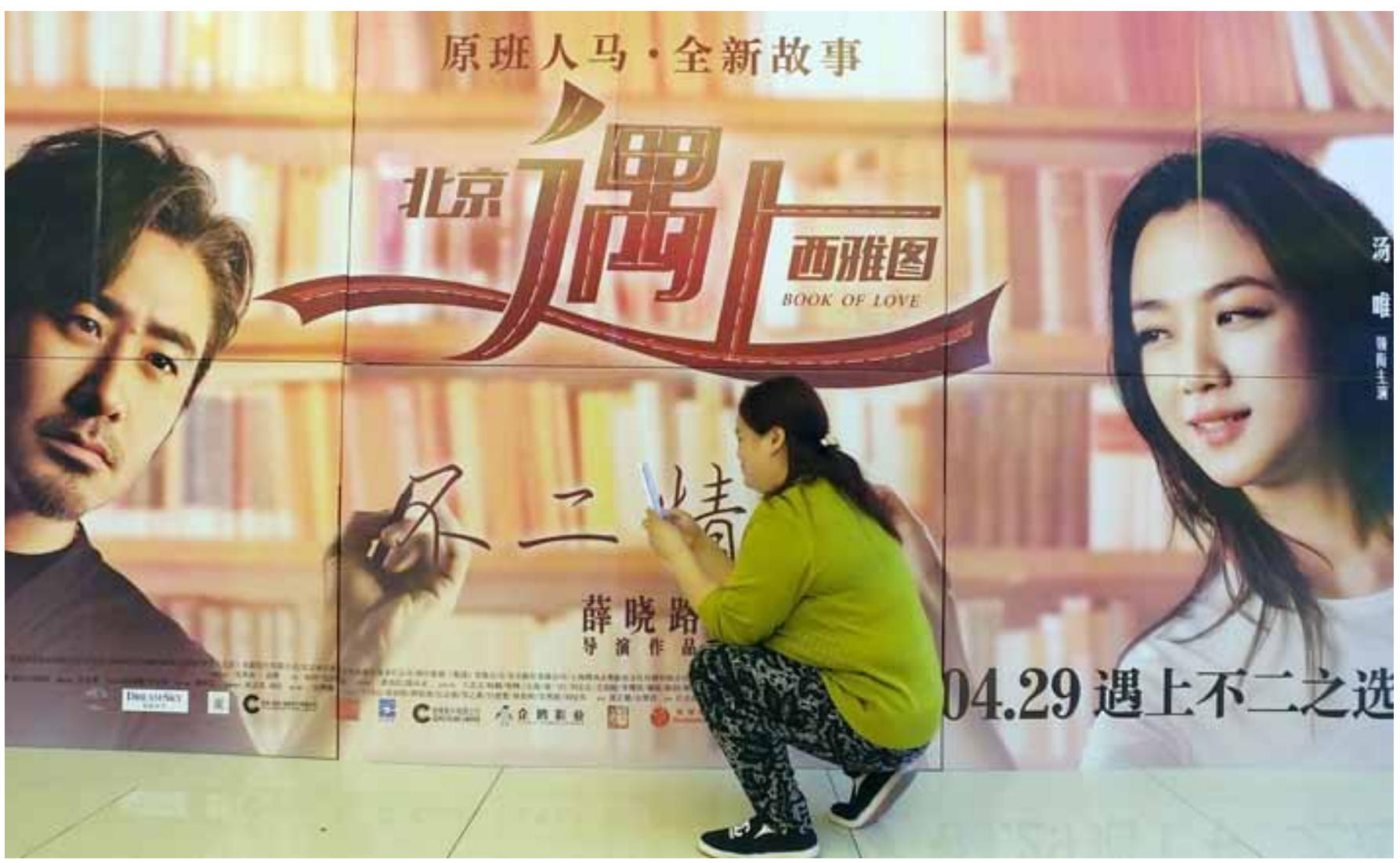

A filmgoer in Yichang photographs a poster for Book of Love, which set records when it opened in cinemas around China in May 2016.

PICTURE: AAP 


\section{LGBTQ ACTIVISM}

\section{The politics of homophobia in South Korea}

JU HUI JUDY HAN

A NOTABLE element of South Korea's general elections in April 2016 was the hypervisibility of antigay political rhetoric, promulgated especially by the fledgling Christian Liberal Party (CLP). An ultraconservative Protestant political party established in March 2016, the CLP ultimately failed to gain a seat in the National Assembly-but it came close, earning 2.6 per cent of votes nationwide, just shy of the 3 per cent required for a proportional representation seat. The increased prominence of formations like the CLP signals a new chapter in religiously charged political homophobia in South Korea.

The CLP has not been alone in injecting explicitly anti-gay political rhetoric into public discourse.

The chairman of the conservative Saenuri party, Kim Moo-sung, has repeatedly described homosexuality as 'an outrage against humanity'. At a Christian political meeting in February 2016, Minjoo Party leader Park Youngsun referred to lesbian, gay, bisexual, transgender and queer (LGBTQ) rights as 'against nature and against God'. She also vowed to oppose any legislation that would protect minorities from discrimination on the basis of sexual orientation or gender identity in employment, housing or healthcare.

Both Kim and Park ranked in the top three in the 22 worst homophobic offenders list compiled by Rainbow Vote, a public education campaign formed to expose politicians with a record of contempt for LGBTQ equality.

There are several key policy areas around LGBTQ equality in South Korea. All involve uphill battles and all provide rich opportunities for coalition-building. One key concern is the prohibition of homosexual conduct in the military, the only instance in which homosexuality is criminalised in South Korean law. LGBTQ activists and legal advocates have called for the repeal of the infamous Article 92 (6) of South Korea's military criminal law that prohibits and punishes sex acts between men even when there is mutual consent. This article is applied broadly not only to criminalise homosexual acts but also to pathologise conduct, appearance and identities that are perceived to be non-normative.

The provision has been documented as being enforced on mere hearsay and allegations, and has been used flagrantly to penalise and isolate sexual minority conscripts who

\section{In their extreme and most}

troubling formations,

homophobia is combined

with Islamophobia and xenophobia already face verbal and physical abuse. Within the system of mandatory male conscription in South Korea, gay men face enormous difficulties in fulfilling their military service obligations safely and with dignity. Several South Korean men have even successfully gained political asylum status in Canada and France, where their fear of homophobic violence and human rights violations during military service were determined to be credible and probable.

At a judicial level, there remains no meaningful and enforceable national anti-discrimination legislation that would extend basic human rights protection to LGBTQ communities in South Korea. The South Korean Supreme Court ruled against legalising same sex marriage on 25 May 2016. Homophobia is a public health issue. People living with HIV/AIDS in South Korea today cannot count on queer-positive medical or hospice care, and face devastating stigma and life-threatening denials of service by medical professionals.

Earlier attempts in 2007 and 2013 to introduce anti-discrimination legislation in the National Assembly were foiled, in large part by conservative Protestant opposition. Similarly, in December 2014, Protestant groups pressured the mayor of Seoul, Park Won-soon-a former human rights attorney and pro-democracy activist-to withdraw his support for LGBTQ rights and refuse to proclaim the Seoul Charter of Human Rights. Outraged by 


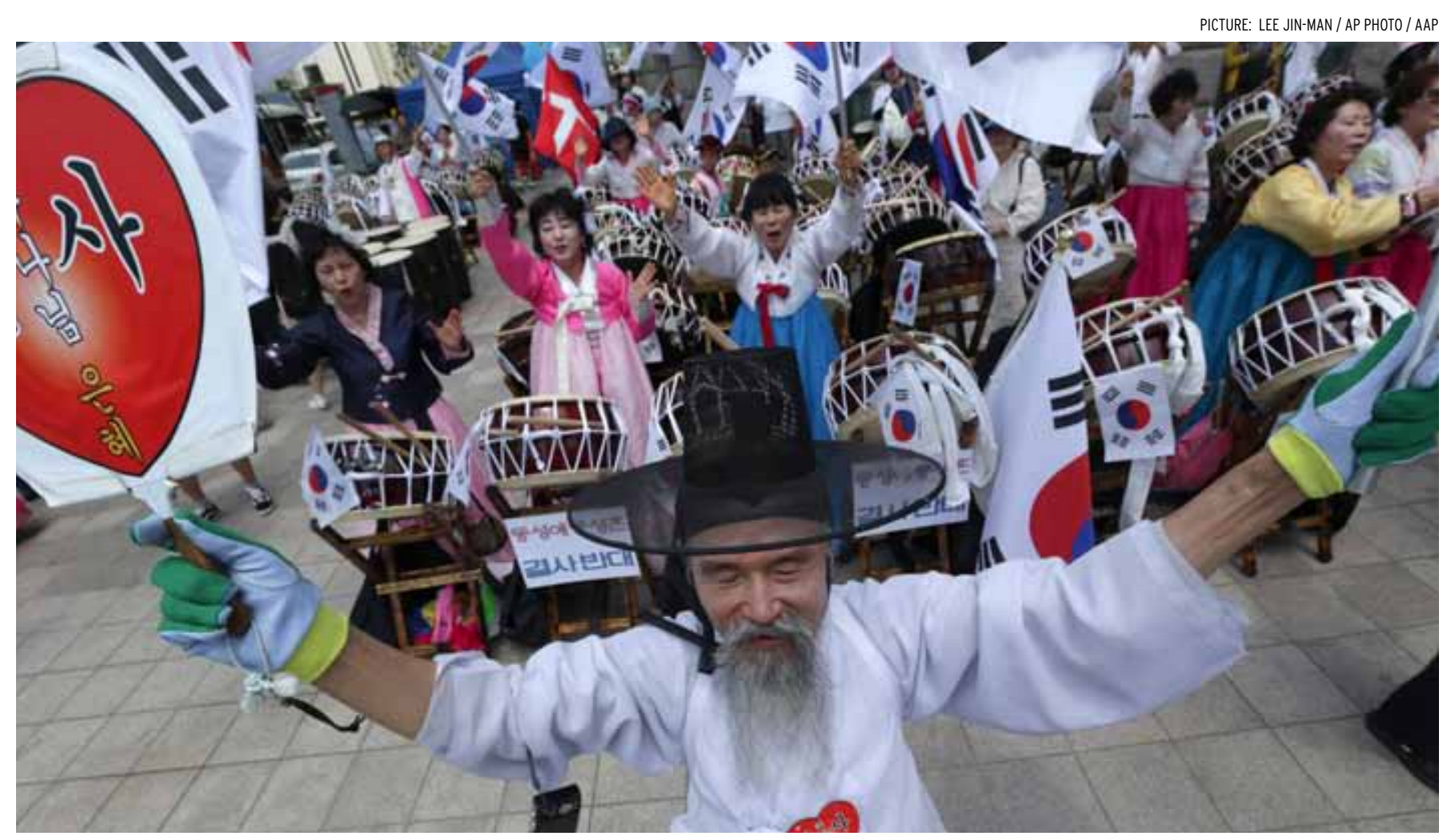

Christian protesters rally against homosexuality and same-sex marriage near the venue of the Queer Culture Festival in Seoul in June 2015.

the mayor's betrayal, hundreds of queer activists and progressive allies from labour and feminist groups occupied Seoul City Hall over six days-an unprecedented political action that demonstrated the growing significance of coalitional solidarity in contemporary LGBTQ activism and minority politics.

Conservative Protestant forces have been particularly unkind to minorities-sexual minorities, immigrants and temporary migrants who constitute religious and ethnic minorities in South Korea, and trade unionists, dissidents and social justice activists who compose formidable political minorities. Conservative Protestants and homophobic political leaders have even linked LGBTQ equality with terrorism and radical Islam, as can be seen in the recent CLP slogans of 'No to homosexuality, no to Islam, no to anti-Christianity', all in the name of national security. Some have gone as far as to call for a stop to immigration from Muslim-majority countries such as Pakistan and Bangladesh. In their extreme and most troubling formations, homophobia is combined with Islamophobia and xenophobia to bring hatred and bigotry to new heights.

In June 2016 the annual Korea Queer Culture Festival (KQCF) in Seoul will celebrate its 17 th year. What first began as a small-scale event with 50 or so participants has now grown to a spectacular festival with more than 10,000 participants and dozens of cultural and political groups that will gather at Seoul Square, in the heart of the city. But increased LGBTQ visibility has also resulted in more public detractors and violent hecklers. In recent years both the queer festival and street parade have been disrupted by anti-gay protesters who have thrown faeces at festival-goers, blocked the parade procession and blasted amplified epithets from outside the festival zone. The $2016 \mathrm{KQCF}$ participants will have to contend with groups that have registered to use Seoul Square for anti-LGBTQ events in the days leading up to the annual queer festival. Homophobia is certainly a public safety issue.

Contention over the queer festival is not simply a struggle over public space. It is a struggle over the public character of that space and the very meaning of a democratic public sphere. It is remarkable that after the spirited slogan in 2015, 'Love, Resist, Queer Revolution', the 2016 KQCF slogan is simply 'Queer I am'. LGBTQ politics in South Korea has come full circle to a sobering and modest demand: an insistence on the fundamental right to be. EAFQ

Ju Hui Judy Han is Assistant Professor in the Department of Geography and Planning at the University of Toronto. 


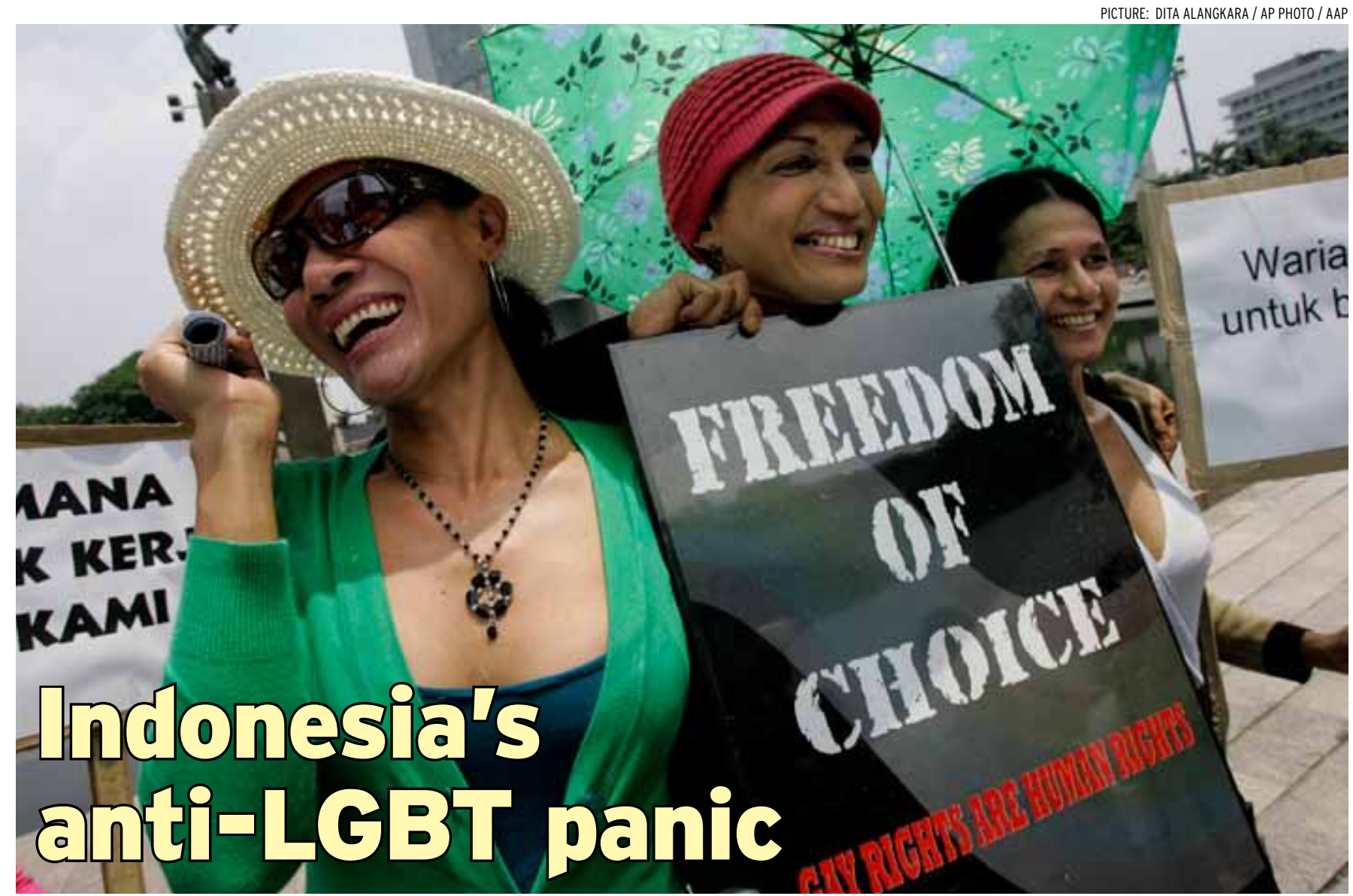

\section{SHARYN GRAHAM DAVIES}

OMPARED with its Asian near neighbours, Indonesia has long been tolerant of same-sex sexuality and transgenderism. Unlike Singapore and Malaysia, Indonesia never criminalised homosexuality and has been accommodating of transgender people-transwoman TV personality Dorce Gamalama, for instance, recently had dinner with President Joko Widodo.

But such visible examples of ostensible acceptance should not obscure the everyday prejudice and harassment that lesbian, gay, bisexual and transgender (LGBT) people face in Indonesia. This prejudice is often perpetrated through the very institutions established to protect citizens, such as the criminal justice system. While there have always been concomitant tolerance and intolerance, events of early 2016 exhibited an unprecedented level of public animosity toward Indonesia's LGBT community.

In January 2016, Indonesia's Technology, Research and Higher Education Minister, Muhammad Nasir, declared that Indonesian universities must uphold standards of 'values and morals' and should not support organisations promoting LGBT activities. The public backlash against this statement forced Nasir to declare that ' $[w]$ e are not against LGBTs but the activity ... the problem is when they are showing romance, kissing, and making love [in public]'.

The worry for Nasir and others was that LGBT would become visible in solidarity-no longer invisible
Indonesian transvestites demonstrate for LGBT rights in Jakarta on the International Transgender Day of Remembrance.

individuals, but a community demanding rights and acceptance. The Speaker of the upper house of parliament added: 'as a movement, the existence of LGBT must be opposed. We must limit its room to move. However, as individual people, they must be protected like any other citizen'.

A primary reason for the subsequent national and international media furore was that Nasir's statement was misreported as a call to ban all LGBT from universities in Indonesia, rather than banning university support for LGBT activities. The furore prompted other Indonesian 
politicians and religious leaders to weigh in on the debate in increasingly sensational terms, perhaps because they felt their homophobic views could be safely espoused or because they thought anti-LGBT statements would win them support.

The conservative Islamic newspaper Republika ran the headline 'LGBT poses serious threat to nation. The Muslim organisation Nahdlatul Ulama said homosexuality was against human nature and called for LGBT activities to be banned. The secretary-general of the People's Conscience Party, which is included in President Joko Widodo's governing coalition, said that 'being LGBT is an infectious and dangerous disease. LGBT must be banned, like we banned communism and drug trafficking. And a former communications minister suggested his one million Twitter followers kill gay people, an act that he claimed was mandated by Islamic law.

LGBT people were framed as a threat to national security, with senior government ministers making claims such as 'LGBT issues can damage national security, identity, culture and the faith of Indonesians.' The LGBT movement was framed as a 'proxy war' funded by Western nations determined to undermine Indonesian sovereignty and brainwash its citizens. UN funding was rejected precisely on the basis that it would help to eliminate discrimination against and violence towards LGBT people.

Indonesia's main psychiatric association weighed in on the debate, announcing in a written statement that homosexuality, bisexuality and transgenderism were classified as mental disorders. Prominent psychiatrists noted that 'we need to promote, prevent, cure and rehabilitate LGBT people' and 'we really do care about them. What we are worried about is that, if left untreated, such sexual tendencies could become a commonly accepted condition in society'.

Indonesia's broadcasting regulator banned the media from portraying LGBT behaviour as 'normal'. Lawmakers supported such moves, declaring that the ban would protect young people 'susceptible to duplicating deviant LGBT behaviours' Calls were made to mandate 'rehabilitation for every person who has LGBT characteristics'. The world's first Islamic school for transwomen, which had recently been celebrated in the international media, was suddenly shut.

Anti-LGBT street protests occurred and pro-LGBT rights demonstrations were suppressed by police. As some local police forces raided places where LGBT individuals congregated, and communities became increasingly vocal in espousing anti-LGBT rhetoric, many LGBT people protected themselves by staying home, changing their address, turning off their mobile phones and ceasing to use social media.

It seems the controversy was spurred by anxiety over LGBT groups becoming visible in solidarity, as suggested by Minister Nasir's insistence that he was not concerned about individuals but rather by LGBT as a collective force, and by subsequent

There was no call for marriage equality despite such calls being made in neighbouring countries comments by other officials referring to the importance of respecting individual, but not collective, LGBT rights.

Such ambiguous attitudes have been on display before. In 2010 the extremist Islamic Defenders Front stormed an International Lesbian and Gay Asia Association conference, attended by 150 activists from 16 Asian countries. A spokesman for the Front declared that 'as long as you are mere individuals committing this sin we don't really care. But as soon as you organise we will fight you'.

Significantly, in early 2016 the LGBT community was not making demands about collective rights. No widespread calls were made for LGBT to 'come out'. In Indonesia an authentic self is not necessarily one that is the same in all situations, and shame works to keep LGBT largely invisible, so that leading a life in the gay world and the straight world is often unproblematic. There was no call for marriage equality despite such calls being made in neighbouring countries, including recently China.

Still, conservative Indonesians were worried about a world where LGBT would take a place at the civil society table, as was increasingly the case elsewhere in the region. Even Singapore had recently acknowledged the economic value of attracting and supporting LGBT foreign talent.

While the 'LGBT crisis' was fashioned at the same time as a revision to anti-corruption law was mooted, there was no guarantee that public debate would focus on the former in favour of the latter. That the 'LGBT crisis' gained traction speaks to simmering anti-LGBT sentiment in Indonesia. It is based on a fear of visible LGBT solidarity, a solidarity that many in Indonesia consider directly threatens national stability. 
Broad social and political factors also played their part in making the panic so virulent. The presence of significant pockets of support for radical forms of Islam that denounce non-heteronormative genders and sexualities meant that intolerant statements made by Muslim organisations and religious scholars were often well received. A toxic level of intolerance for diversity is shown in the fact that an Islamic leader and former cabinet minister was not officially reprimanded for exhorting his Twitter followers to kill LGBT people.

The suggestion that LGBT groups were being supported by foreign powers in efforts to undermine Indonesian security was exacerbated. While there are long-standing fears within Indonesia of outside interference and foreign cultural influence that predate the LGBT crisis, the idea of Western encroachment was again triggered in the wake of revelations that Australia had spied on Indonesia, and by Indonesia's execution of Australian drug smugglers.

Adding to this, ongoing poverty and rising inequality mean that LGBT people often become targets for more general frustrations. Rising inequality adversely impacts citizens on all levels of the socio-economic ladder resulting in widely expressed anti-LGBT sentiment. And high social media uptake in Indonesia ensures that hashtags such as \#rejectlgbt and online expressions of outrage over issues as small as same-sex emojis receive widespread exposure.

Underlying these factors is a fundamental state ideology of heteronormativity-described as 'state straightism' by the American anthropologist Tom Boellstorff-that considers any expression of
Punitive surveillance and penalisation of

\section{non-marital sexuality has}

disastrous consequences

for all citizens

non-marital heterosexuality as potentially destabilising and thus something to be controlled through force. Control of sexuality is, of course, not new. But in Indonesia the government has never previously directed policy against LGBT people in particular. My research suggests that while private extra-marital heterosexuality is punitively policed, private individual homosexuality has often escaped popular surveillance. Now this is increasingly not the case.

When President Suharto resigned amid social upheaval in 1998, he left citizens both excited about a future that promised democratic freedom and worried about who would oversee their moral welfare. Suharto had positioned himself as father of an explicitly heteronormative nation and guardian of citizens' morality. Overt controls exerted by Suharto's New Order regime left no need to impose specific policies aimed at regulating homosexuality-the threat to national stability was primarily considered to come from nonmarital heterosexuality. Of course, there were regulations regarding the former-including a heavily censored media requiring audiences of LGBTthemed films to imagine their own queer endings-but never specific homophobic policies.

For many Indonesians Suharto's departure left a moral void. Voices espousing punitive sexual surveillance comforted those fearful of an imagined future sexual liberation. That the social, political and religious precursors to the 2016 'LGBT crisis' date to the time immediately after Suharto's downfall seems no coincidence. As well, post-September 11 discourse vilified Islam and drove some disaffected Muslims towards an extremist ideology that penalises nonmarital sexuality. The conservative turn in Indonesian politics predates the fall of Suharto and September 11, but these two events mark watersheds in anti-LGBT sentiment.

The regulation of sexuality between Suharto's demise and 2016 was almost solely focused on non-marital heterosexuality. For instance, an analysis in 2014 of documents on the website of the Islamic Defenders Front vigilante group revealed numerous articles and postings about the evils of promiscuity. By contrast, I could only find four mentions of the evils of homosexuality.

The first political move in terms of sexual regulation was the passing of the Anti-Pornography and Pornographic Acts Law in 2008. Among other things, the law paved the way for individuals appearing in sex films to be prosecuted. The most famous case involved rock star Ariel and his girlfriend. The judge expressed concern that people would copy Ariel's behaviour and while Ariel argued that consenting private activities should not be the subject of law, the judge disagreed and sentenced Ariel to prison.

Red light districts have been regularly raided and demolished in attempts to eliminate prostitution. Both sex workers and clients have been arrested. Even policewomen are not immune to sexual surveillance: during 
recruitment, female candidates must be willing to undergo a two-finger 'virginity test'. The police response to a 2014 Human Rights Watch report denouncing the test was summed up by a senior officer's rhetorical question: 'Do you want prostitutes joining the police force?'

The 2016 'LGBT crisis', though, is the first time in Indonesia's history that LGBT people have been systematically targeted through proposed policy changes. The crisis stems from fear that any non-marital sexuality can challenge the heteronormative foundation of Indonesian nationhood.

Punitive surveillance and penalisation of non-marital sexuality has disastrous consequences for all citizens. Beyond the violation of individual rights to sexual freedom, if people are afraid to access sexual health care, do not report sexual crime, and are too ashamed to discuss sexuality, broader society is negatively impacted. For instance, Linda Bennett of the University of Melbourne has revealed how male doctors in Indonesia are too embarrassed to say the word 'vagina'-let alone examine one-leaving women seeking IVF treatment to endure infertility because of an undiagnosed STI.

The 2016 'LGBT crisis' can be read as an extension of the surveillance and control of all non-marital sexualities to Indonesia's LGBT communitycontrol exerted by those vying for power in a decentralised and volatile state. Sexual equality, like equality in general, results in a better world for all and is a most worthy fight. EAFQ

Sharyn Graham Davies is Associate Professor at the School of Social

Sciences and Public Policy, Auckland University of Technology. Her research focuses on gender and sexuality in the Indonesian archipelago.

\section{Religion, gender and the state in Indonesia}

\section{KATHRYN ROBINSON}

$\mathbf{R}$ ELIGIOUS identity and gender relations are integral to women's experiences of citizenship in Indonesia. While around 88 per cent of Indonesia's population is Muslim, it is emphatically not an Islamic state, in which state law and Islamic law are coterminous. So what is the relationship of religion to citizenship rights for women in the Muslim majority?

Religious prescriptions affect women's rights, most notably in the area of marriage law and rights within the family. In the Dutch colonial period, family law was largely left to Islamic authorities. But during its slow spread through the archipelago, Islamic law accommodated itself to the existing practices there, particularly in regard to polygyny and property rights: the former was unpalatable in much of the archipelago, and indigenous customs commonly recognised women's inheritance and other property rights.

Activist women in the nationalist movement successfully pressed for pro-women government regulations in regard to Islamic marriage, especially polygyny, child marriage and divorce by repudiation. Women's activism continued in post-independence Indonesia and by 1974 they achieved some of their goals with the passage of a national marriage law. It set a minimum marriage age and gave greater protection in matters of divorce and polygyny. Efforts to standardise Islamic laws in 1997 further strengthened some customary rights, including women's common property rights on divorce.

But these successes cannot be taken for granted. In the democratised political space that opened up after the fall of Suharto in 1998, women activists argued for a revision of the 1974 marriage law to ban polygamy and further limit men's prerogatives in divorce. At the same time, some men (together with women supporters) took advantage of the freer political climate to unsuccessfully campaign for the restoration of rights to polygyny, which many argued was a religious entitlement.

Individuals and groups identifying as Islamic feminists have championed women's marriage rights and revision of the law. They argue that the Qur'an fundamentally supports a society of equality. But the opening up of democratic space also created room for anti-liberal Islamic groups, called keras (hard), whose view of Islam encompasses the expression of masculine prerogative.

In 2008, noisy street demonstrations by (usually male) supporters of groups like the Islamic Defender's Front effectively pressured the national legislature to pass a socalled 'anti-pornography' law, which largely targeted women who failed to meet dress standards or engaged in 
proscribed 'pornographic' actions in public. 'Hard' Islamic groups argued that restrictions on women's dress and behaviour were expressions of Islamic orthodoxy.

Champions of women's rights opposed the bill on the grounds that it was largely an attempt to restrict women's freedom of movement. It was also strongly opposed by nonMuslims in Bali and Papua who argued for the rights of women to bare breasts in public as a historic cultural norm. While the law has largely lain dormant since its passage, it has been a lightning rod for opposition by women who regard it as emblematic of official attempts to limit women's freedom in the name of Islam.

Islamic rhetoric accompanied another limitation of women's rights as citizens in the post-Suharto period, this time linked to the 'big bang' decentralisation of political authority to local government. Many newly empowered districts enacted local bylaws purportedly based on sharia law. These local regulations mainly targeted women: curfews, restrictions on their movement in public, dress codes (especially the requirement to wear the jilbab or tight veil) and recently in Aceh a ban on women sitting astride motorcycles. In 2015, Human Rights Watch reported that 279 local regulations discriminated against women, 90 of them requiring women to wear the jilbab. In some cases this requirement has been imposed on Christian women.

Women, including Islamic feminist activists, have contested these regulations - and they are also frequently ignored. However, they have licensed vigilante acts by radical groups and arbitrary enforcement by local government agencies against women appearing in public without the veil or after curfew. In West
Indonesian women from

\section{all religious backgrounds}

\section{have been active in}

politics at local and

national levels

Java, factory shift workers have been harassed and accused of 'immoral' acts when returning home from work. Significantly, not all the politicians championing these anti-woman regulations represent Islamic parties. Rather, the rules seem to be a product of populist strategies that use an Islamic idiom to court male voters with promises to sustain masculine prerogatives by controlling women.

While there have been some attempts to use religion to limit women's participation in politics, Indonesian women from all religious backgrounds have been active in politics at local and national levels. Laws requiring gender quotas for political parties' parliamentary candidates were enacted in 2008, and currently 17.5 per cent of seats in the national parliament are held by women. Women's involvement in public life also shows that Islam cannot be singled out as being hostile to women's rights. It is predominantly Hindu Bali that has the lowest levels of women's political participation. In spite of the 2008 quota, Bali is one of three provinces where women are not eligible to vote in the influential neighbourhood-level political units known as banjar.

Of the three parties that achieved more than 20 per cent female representation in the 2014 elections, one was the Islamic party PKB, which is closely associated with Indonesia's largest Islamic organisation, the moderate Nahdlatul Ulama (NU). The other two were secular nationalist parties. PKB's success in getting women into parliament reflects the large number of women in NUaffiliated mass organisations.

Many of the diverse communities of the archipelago have had notably tolerant attitudes to individuals who are outside the constraints of a gender binary, from transgender entertainers to priests of customary religions. Yet in recent years Indonesia's tolerance is showing some cracks.

Visiting Muslim lesbian feminist author Irshad Manji, for example, was subject to attacks by radical Islamic groups in 2012. In recent months there have been increased levels of violence against LGBTI individuals, commonly justified in the name of Islamic orthodoxy.

The reactionary groups that seek to restrict the rights of women and deny those of LGBTI individuals are seen by many Indonesians as expressing a foreign, 'Arab-influenced' variety of Islam which deviates from what the prominent Indonesian scholar Azyumadi Azra has called Indonesia's 'colourful' — and tolerant-religious traditions. Despite radicals' rejection of what they condemn as alien 'Western' ideas about sexuality and gender, it is perhaps these openminded religious traditions that are still most at home in Indonesia.

Kathryn Robinson is Emeritus Professor at the School of Culture, History and Language, The Australian National University, and author of Gender, Islam and Democracy in Indonesia (Taylor E Francis, 2009). 


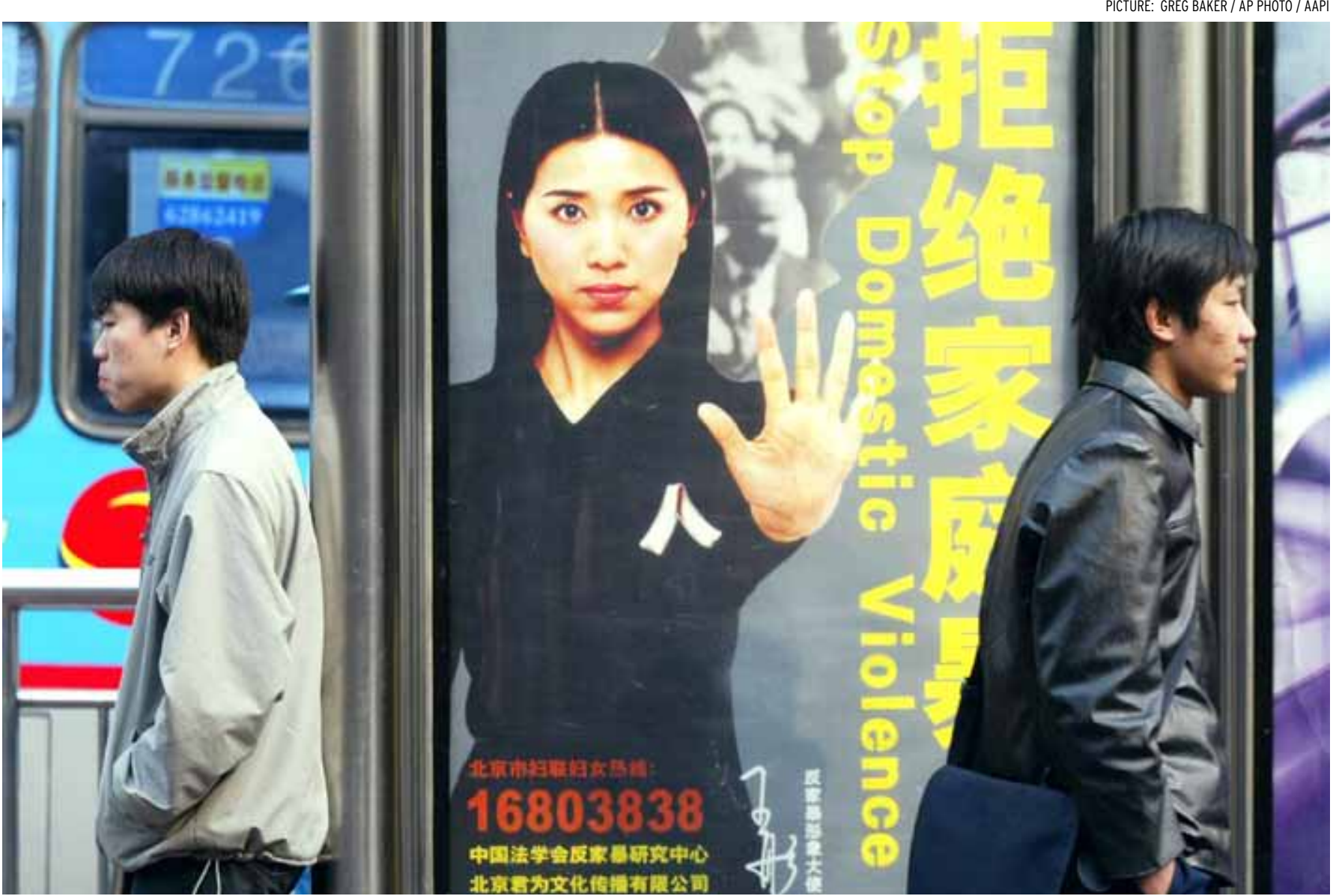

Stop! This billboard on a Beijing street was part of a national campaign to end domestic violence, but legal provisions have to overcome cultural norms.

\section{Domestic violence: why legal change alone is not enough}

\section{CHEN TINGTING}

HINA'S first national law against

$\checkmark$ domestic violence came into effect on 1 March 2016. The law marks a significant step forward from the country's existing legislation by legally defining domestic violence and extending legal protection to victims. Yet a fundamental cure for the epidemic of domestic abuse-which disproportionately affects womenrequires further efforts to change persisting misperceptions about women's moral responsibilities and domestic violence itself.

The new law's immediate effect was seen in a wave of media coverage spotlighting domestic violence cases, including the deaths of two women around the time it came into force. A consistent thread in these women's stories was an inability to leave the abusive relationships or to disclose their suffering. A victim's decision not to make a complaint to the policewillingly or unwillingly - can easily undermine the ability of the new law to uphold justice.

In China, domestic violence cases are processed under the principle of 'no trial without complaint'. The new law allows close relatives to file a complaint on behalf of victims who may not be able to do so on their own. This would then allow police or women's federations to request restraining orders from the courts.

Public education surrounding the law should equip citizens not only with the knowledge of how to help themselves, but also of how to assist 
domestic violence survivors around them to seek justice. But would citizens really stand up and provide this assistance, even if they were better educated about the law?

In China, defending marriage is typically considered a primary moral responsibility for women. The shame of failing to do so has confined many victims in abusive relationships and constrained people around them from offering appropriate help. Despite the rising divorce rate, Chinese women still face enormous pressure to get married and stay married. Many victims are told to bear the pain of domestic violence, which is often confused with lovers' quarrels and normalised by the claim that 'most women have endured it.' Victims are usually advised not to divorce for the sake of the family's reputation and their children's wellbeing, due to the pervasive belief that children need to grow up in a 'complete' family.

Two months before her death, 25-year-old Li Hongxia posted on social media that she felt her life was in danger from her husband. Most of her friends, and her own mother, discouraged her from seeking a divorce. She was soon hospitalised after another abusive attack and was then strangled to death by her husband at the hospital.

Common misperceptions about the nature of domestic violence also create challenges for effective intervention. Violence is often ascribed to women's misbehaviour or rebellion from their 'proper' gendered roles. The reality is that domestic violence is about unequal power relations between partners and the abuser's control over the victim, rather than any wrongdoing on the victim's part. Yet this goes generally unrecognised in China.

Unequal power dynamics between the abuser and the abused are not always determined by relative financial security. Perhaps more fundamentally, these power dynamics are often based on gender norms. Contrary to the popular myth that victims of domestic violence are usually financially dependent or less educated, many women who are universityeducated and even providers for their households are also victims of domestic violence.

Violence can occur when traditional masculine authority is challenged. Zhang Xiaoyan, a 34-year-old female doctor, was abused for years and died of poisoning in March, allegedly murdered by her former husband. Zhang owned a clinic and a pharmacy, and was the only breadwinner for the family. Even after they divorced, her ex-husband continued to control her, preventing her from moving out by threatening her daughter and her parents.

It would surprise many modern and independent Chinese women how deeply rooted regressive perceptions on domestic violence are in certain segments of Chinese society. Zhang

It's no surprise that

preventative measures and other responses to domestic violence... are generally constructed for the ultimate goal of fixing the marital relationship
Xiaoyan's neighbours and co-workers didn't intervene when they saw her with bruises or a broken leg, or even when they witnessed the abuse happening. The same media that publicises the new anti-domesticviolence law also offers tips to women on changing themselves in order to 'win back' their husbands, and romanticises the 'love' between selfcentred, dictatorial men and their 'princesses'.

The importance of family integrity is further reinforced by modern political discourse in China, which defines social stability as the foundation of governance and development. The family, which is based on a marriage contract between a man and a woman as defined by Chinese law, is seen as the fundamental institution of society. It's no surprise, then, that preventative measures and other responses to domestic violence, in all but the most extreme cases, are generally constructed for the ultimate goal of fixing the marital relationship, rather than defending the rights of the abused. Mediation is still the primary method used to resolve domestic violence cases.

The new law-a result of almost two decades of campaigning driven by China's civil society groupsis a manifestation of the state's commitment to addressing domestic violence. But it will take a more insightful public education campaign, and a firm commitment to upholding human rights, to transform the underlying mindset that currently constrains further progress. Until then, the path to ending domestic violence will be a long one for China, as elsewhere. EAFQ

Chen Tingting is The Asia Foundation's program officer for women's empowerment in China. 


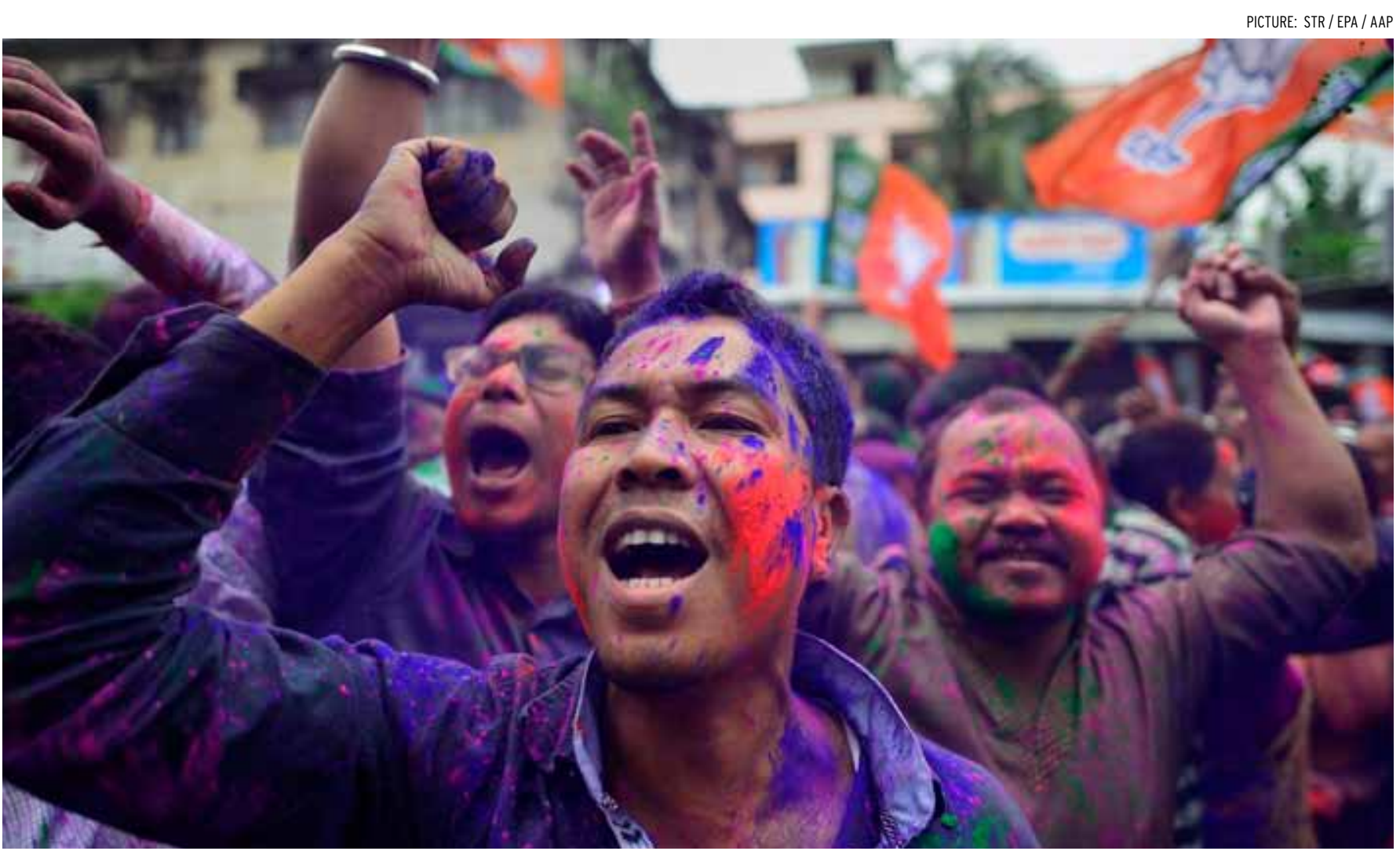

Bharatiya Janata Party supporters celebrate in the streets of Guwahati after their party won a majority in the Assam Assembly in May 2016.

\section{Making federalism work for India}

\section{GOVINDA RAO}

I

N ECONOMIC terms, the federal system was created with the intention of maximising economies of scale, while still providing public services to cater to people's divergent preferences. But there is more to federalism than just the economics. In political terms, federalism involves building a strong national polity by combining sub-national entities, and by providing an adequate political space for them to exist within a broader national polity. And in emotional terms, federalism provides a national bond while permitting multiple local identities to be retained.

For a country such as Indiainhabited by over 1.2 billion people with wide social, ethnic, religious, linguistic and economic diversitiesfederalism is not an option but an imperative. But, for India, full realisation of the advantages of federalism depends on the extent to which its various players can cooperate and combine within the federal system.

Fiscal federalism in India has evolved considerably over the past 69 years and now holds the country together, providing identity and scope to various religious, ethnic and linguistic groups as well as a reasonably flexible institutional framework for multilevel governance. But the system has not worked for everyone. There remains a great deal of scope for improvement. Developing the country and improving the wellbeing of its people can only be achieved within a strong institutional framework that combines the advantages of a free market economy 
with those of competitive regional governments.

The 40 years after independence were marked by restrictions on the market as well as sub-national governments. Resource allocation was dictated by national priorities and centralised planning restricted the role of the subnational governments. It was not until 1991 that the Indian government realised that planned development strategies undermined the roles of the market and subnational governments in accelerating growth, reducing poverty and ensuring human development.

Although India's growth rate has steadily accelerated-from an average of 3.5 per cent during the first 40 years of independence to 7.5 per cent since 2001-there is a growing awareness that this is still far below India's growth potential. Possible reasons for this include the difficulties in building consensus on reforms in a democratic polity and the ability of special interest groups to impede reform.

But a more important reason for India's underwhelming growth performance is the lack of coordination between its seven union territories and 29 states in carrying out reforms.

In the Indian constitution, the Seventh Schedule assigns functional responsibilities to Central and State governments in terms of 'union', 'state' and 'concurrent' or joint subjects. Taxes are then assigned according to whether the union-that is, the central government-or the states have jurisdiction. But this separation only exists in the legal sense and there is considerable overlap in the tax bases. For example, taxes on agricultural incomes and wealth are assigned to the states, whereas taxes on non-agricultural incomes and wealth can only be levied by the union
India must put in place

\section{a mechanism to ensure}

a greater degree

of cooperation and

\section{coordination between the}

\section{union and states}

government. This makes the levy of comprehensive income tax extremely difficult and has opened up a major avenue for tax evasion.

The proposed comprehensive goods and services tax (GST) faces similar problems. The GST has become difficult to implement because states that have the power to levy sales taxes on goods cannot also levy taxes on services. The union has the power to levy excise duty on all manufactured products-which is actually a sales tax at the first point of sale-but cannot extend the tax to subsequent stages. While there have been serious attempts to levy the GST at both union and state levels for about a decade, the exercise has been mired in political gamesmanship and lacks the political consensus required for a constitutional amendment. Hopefully, the current session of parliament can reach an agreement and pave the way for reforms that will raise revenue productivity and promote export competitiveness.

When it comes to expenditure, a considerable degree of cooperation is necessary to enable both the union and states to provide diversified public services while reaping the cost advantages arising from economies of scale. But the necessary level of cooperation is not currently present in India. As with taxes, India's constitution assigns separate expenditure functions to the union, state and concurrent governments. This results in significant overlap between concurrent sectors, such as energy, environment and education. Instead, India must put in place a mechanism to ensure a greater degree of cooperation and coordination between the union and states, while still promoting healthy competition.

One example where such cooperative federalism is particularly lacking is anti-poverty measures. Much of the funding for anti-poverty interventions has to be defrayed by the central government, but these programs are then implemented at a subnational level.

The union's role is also often uncoordinated as it must cover some costs to ensure minimum standards are met, regardless of whether the public services in question fall within the union category of spending or not. Even where the union is legally responsible, different local conditions mean that it is sometimes necessary to use the states to deliver services.

Another area in which the union and states have to work together is in ensuring healthy intergovernmental competition. US economist Wallace Oates called this 'laboratory federalism. Ensuring a measure of competitive equality among the jurisdictions and avoiding predatory competition through effective regulation is critical to reaping the gains from intergovernmental competition. Therefore, there must be a clear mechanism to ensure coordination, promote cooperation and activate healthy competition among the states.

In general, the asymmetry between 
tax powers and expenditure functions is a feature seen in all federations. General purpose transfers by way of tax devolution or block grants enable the states to provide comparable levels of public services at comparable tax rates. It is also important to ensure those public services that are subject to nation-wide externalities meet minimum quality standards. This can be achieved through specific purpose transfers.

In India, the constitution provides for tax devolution and block grants from the union to the states based on the recommendation of the Finance Commission, a constitutional body appointed by the president every five years. So far, 14 Finance Commissions have made recommendations, which have then been generally accepted and implemented.

But questions have been raised on the design of general purpose transfers as they do not fully offset the states' fiscal disabilities and they create adverse incentives on tax effort and expenditure. The 14th Finance Commission has attempted to meet these challenges by increasing the tax devolution to the states from 32 per cent of the divisible pool to 42 per cent. This means consolidating all general purpose transfers including those given by the old Planning Commission.

The major problem is in the disbursement of specific-purpose transfers. These are given by various central ministries ostensibly to ensure minimum standards for public services for all citizens irrespective of their place of residence. The existing centrally sponsored schemes face several difficulties in terms of number of services chosen for equalisation, their one-size-fits-all design, and the inability of many of the states to match union contributions. Transfers to a large number of schemes further results in a thin spread of resources.

After assuming power, the National Democratic Alliance (NDA) government appointed a committee under the Chief Minister of Madhya Pradesh, Shivraj Singh Chouhan, to rationalise the various transfer schemes. But even after consolidation, there are more than 30 schemes with uniform matching contributions of 40

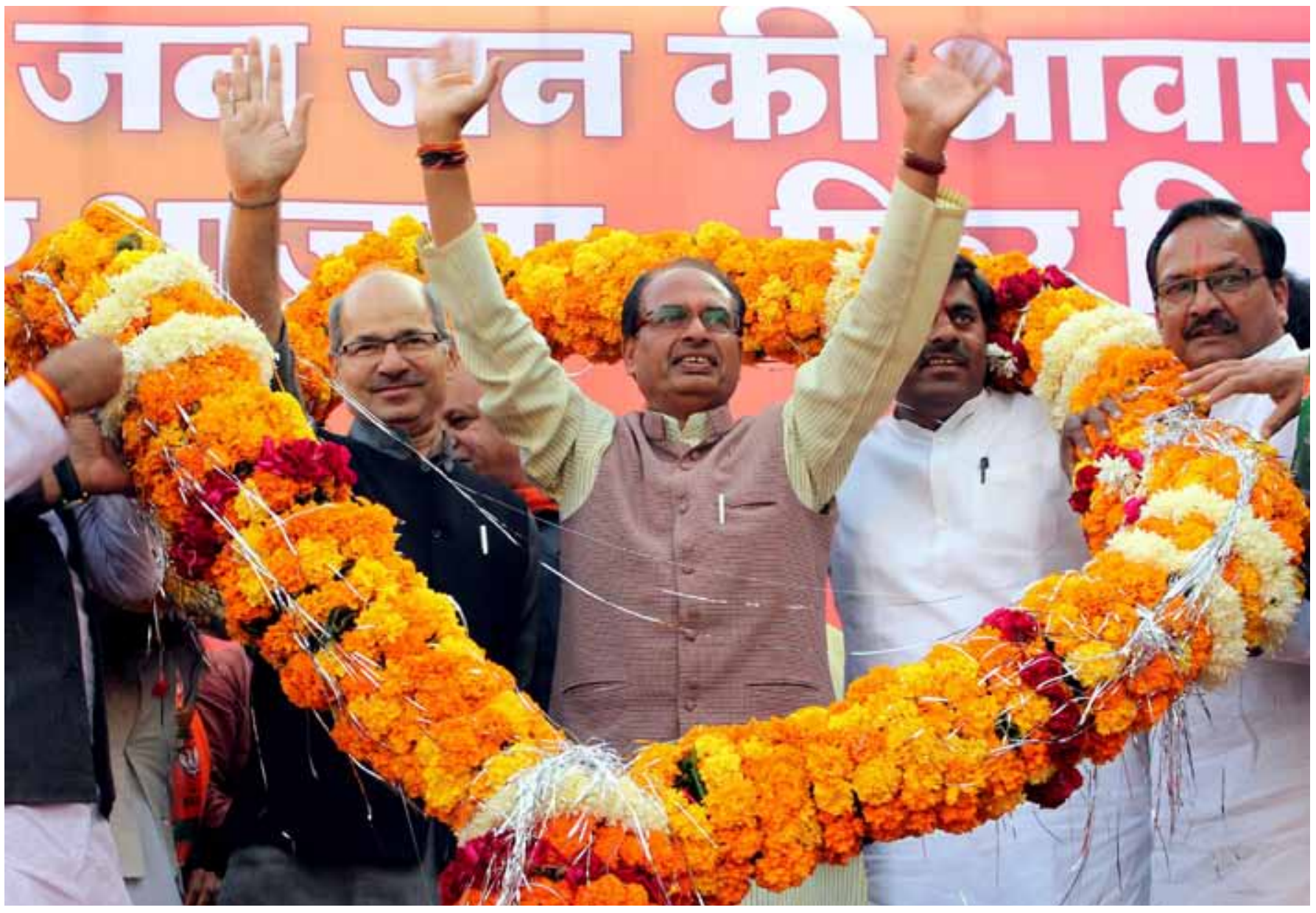

The Chief Minister of Madhya Pradesh, Shivraj Singh Chouhan, waves to supporters during an election rally in Bhopal in November 2013. He won comfortably. PICTURE: SANJEEV GUPTA / EPA / AAP 
per cent of the cost required from the states. With such a large number of available schemes, it is impossible to link a tangible outcome to a specific transfer. These schemes seem to serve a political purpose rather than ensuring minimum standards.

The most important requirement for the successful working of a federation is an institutional mechanism for intergovernmental coordination, bargaining and conflict resolution. In India, such a mechanism is necessary to foster a spirit of trust and cooperation between the union and the states, enable intergovernmental bargaining, resolve conflicts and regulate intergovernmental competition.

At present, no such institution exists. This has resulted in little coordination or conflict resolution, and a multitude of ad-hoc arrangements. Yet with the end of single party rule in both the union and states, alongside the emergence of coalition governments at the union level, a formal institutional mechanism has never been more necessary to minimise the transaction costs of multilevel decision-making.

The Indian government has tried to address this institutional failing by setting up the Inter-State Council under the provisions of Article 263 of the constitution. Yet instead of setting up an independent neutral institution, the government constituted the InterState Council under the Union Home Ministry.

Similarly, the National Development Council (NDC) was constituted in 1950 to facilitate collaborative planning exercises. It comprises members of the union cabinet, the deputy chairman and members of the Planning Commission, and the chief ministers of the states. Rather than being a cementing institution and a

PICTURE: RAJANISH KAKADE / AP PHOTO / AAP

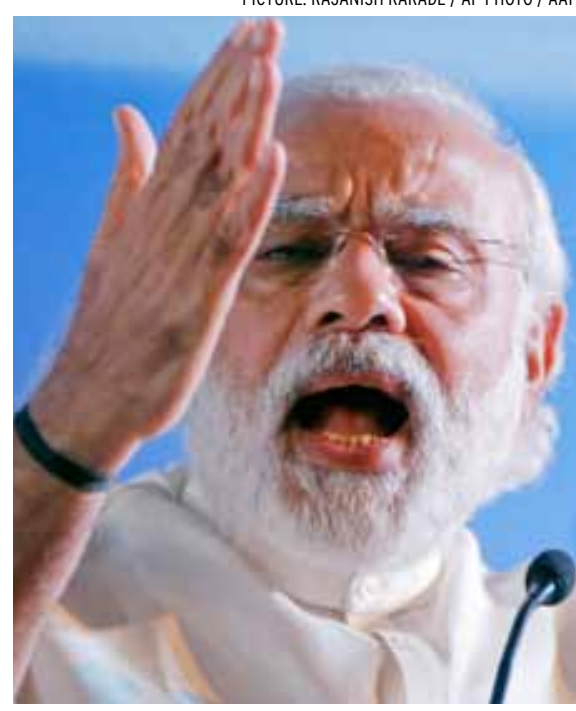

Prime Minister Narendra Modi, whose government has created the National Institute for Transforming India to replace the Planning Commission.

neutral referee, the NDC became a speech making body and its meetings a forum for voicing opinions and grievances. With the abolition of the Planning Commission, the NDC too has seen its last meeting.

In 2015, the Modi government replaced the abolished Planning Commission with the National Institute for Transforming India (NITI Aayog). One of its mandates is to promote cooperative federalism and enable healthy intergovernmental competition. It is important that NITI Aayog should be upgraded to a constitutional body rather than

\section{Decentralisation is ...}

\section{essential to ensure}

effective delivery of public

services that respond to

people's requirements one based on a cabinet resolution. Hopefully, with time, the Inter-State Council will be merged with NITI Aayog to become an independent constitutional body. If so, it can then undertake the important tasks of promoting trust and cooperation between the union and the states, regulating intergovernmental competition to avoid predatory competition and promoting harmonious development in the country.

One of the most significant failings of Indian federalism is the lack of effective decentralisation below the state level. Some of India's states are larger than many countries. Decentralisation is, therefore, essential to ensure effective delivery of public services that respond to people's diversified requirements. While decentralisation is extremely popular among most Indian states this is only true up to a point. For instance, despite amendments to the constitution to devolve powers to urban and rural local governments, most states have failed to do so.

Making federalism work for India requires substantial reform of federal institutions and a general decentralisation of policy. But, more importantly, federalism also requires the harmonious participation of diverse groups. Without this, nationwide product and factor markets cannot operate smoothly. Similarly, for optimal efficiency in service delivery and accountability, it is important to foster the spirit of cooperation and intergovernmental competition. EAFQ

\section{Govinda Rao is Emeritus} Professor, National Institute for Public Finance and Policy, New Delhi, Senior Adviser, Deloitte Touche Tohmatsu India, and Chief Economic Adviser, Brickwork Ratings. 


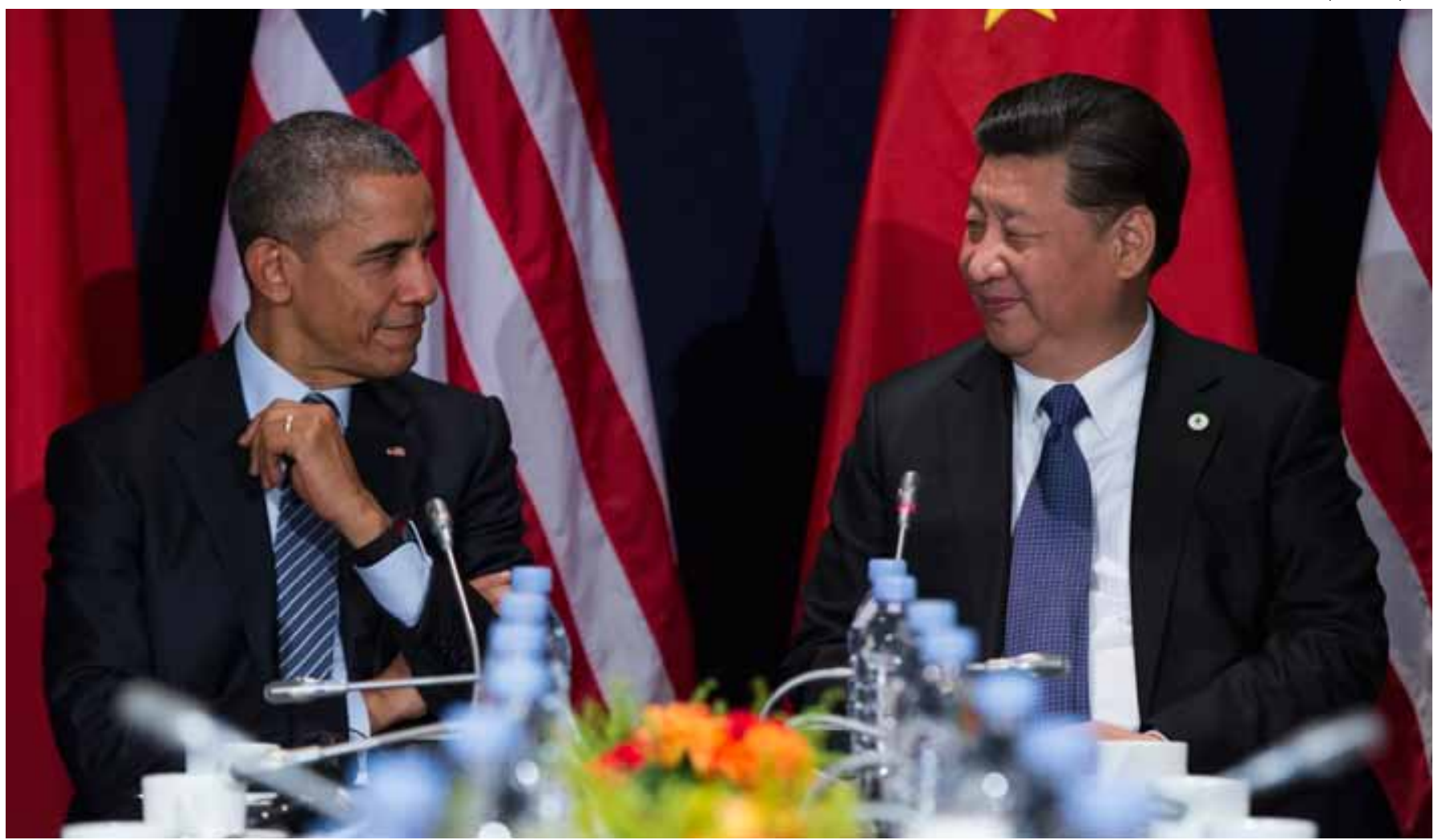

US President Barack Obama and Chinese President Xi Jinping: on the economic order, it is not hard to imagine an accommodation of US and Chinese interests.

\section{What might a new Asian order look like?}

ROBERT A. MANNING AND JAMES J. PRZYSTUP

N NUMEROUS essays, Hugh White has argued that the US-led Asia Pacific order, which he rightly views as a source of peace and growing prosperity over the past 70 years, is increasingly outmoded. As daily events in the South China Sea attest, the current order is increasingly contested. White fears an Asia caught in the middle of a dangerous US-China rivalry that could spark conflict between the two nuclear powers.

White argues that 'It is too easy to assume that the only alternative to US primacy in Asia is Chinese primacy'. Instead, Asian leaders need to think creatively as 'there are many other possible foundations for a new Asian order, which would serve the interests of all of us, including the United States and China'.

Perhaps. On the economic order, it is not difficult to envision an accommodation of US and Chinese interests. China has worked within the WTO system. The Trans-Pacific Partnership and the Regional Comprehensive Economic Partnership are not incompatible and over time hold the prospect for integration.

China is not challenging the IMF.
The Asian Infrastructure Investment Bank, which some feared Beijing would push as an alternative to the Bretton Woods system, appears to be on a trajectory to define its structure, governance and transparency as being compatible with the World Bank and Asian Development Bank (with which it is already pursuing co-financing). Clearly the 'win-win' vision of an integrated, inclusive Asia Pacific economic order is feasible, if not already taking shape.

But even as regional economic integration continues apace, the security environment is marked by increasing defence budgets, 
confrontation and rising nationalistic territorial disputes. It is here that US and Chinese competing visions of regional order are sharply defined, with no resolution in sight.

The hope that China's economic opening, reform and integration into the global economy could bring about domestic political liberalisation and constrain China's international behaviour has not fared well. No one has yet offered a viable middle ground between the current US-centric architecture and Xi Jinping's call for a new security architecture of 'Asia for Asians'

As for the region's present security architecture, what we are witnessing is an evolution from the Cold War 'hub and spokes' model to a more open architecture, fostering security cooperation between with US allies and partners as well as between them. There is increased cooperation bilaterally between Japan and Australia, and Japan and the Philippines, trilaterally between the US-Japan-Australia and US-JapanSouth Korea, as well as quadrilaterally between the US Japan, Australia and India.

At the same time, the United States has developed comprehensive partnerships with Indonesia, Malaysia and Vietnam, new basing arrangements in the Philippines and a strategic partnership with Singapore.

This meshes nicely with the evolving intra-Asian security partnerships. Japan and Australia have developed comprehensive and strategic partnerships with Malaysia, Singapore and Vietnam. India is installing data tracking capabilities in Vietnam. Within the partnership construct, the United States, Japan and Australia are working with countries bordering the South China Sea on initiatives aimed at maritime capacity

The hope that China's economic opening, reform and integration into the global economy could bring about domestic political liberalisation and constrain China's international behaviour has not fared well.

building and enhanced maritime domain awareness, joint training, exercising and port calls.

Earlier this year a Japanese submarine made port calls in the Philippines and Vietnam, which would have been unimaginable even five years ago. And US port calls are coming soon to Palawan and Subic Bay in the Philippines and Cam Ranh Bay in Vietnam.

So why is this happening? China's assertive nationalist behaviour since

PICTURE: MIKHAIL METZEL / AP PHOTO / AAP

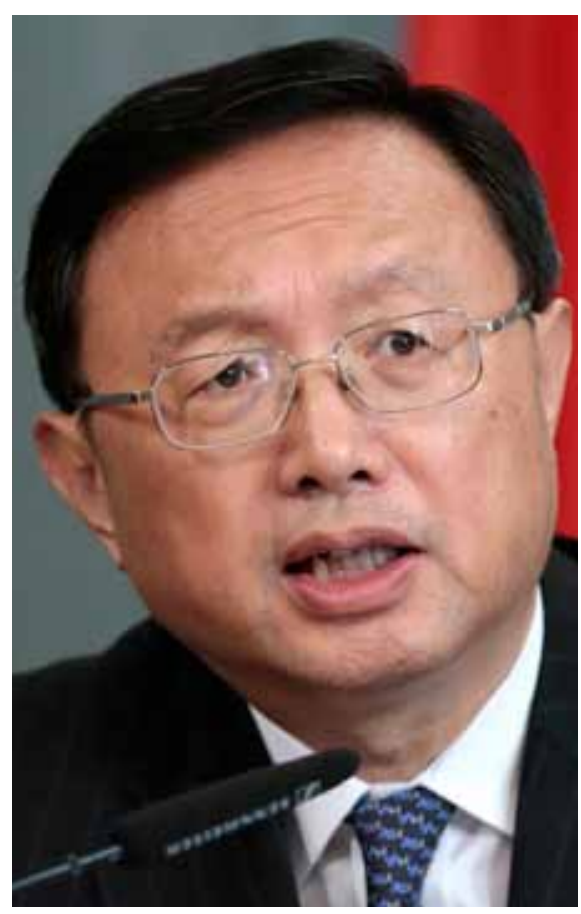

Former Chinese foreign minister Yang Jiechi, who told delegates at the the ASEAN Regional Forum in 2010: 'China is big. You're small. That's a fact'. the global financial crisis has sparked a bandwagon effect among Asian countries towards the United States and each other. Take, for example, the behaviour of then foreign minister Yang Jiechi at the ASEAN Regional Forum in Hanoi in 2010, after then secretary of state Hillary Clinton's offer of US assistance to resolve South China Sea disputes. After his walkout Yang returned and reminded the Southeast Asian nations that 'China is big. You're small. That's a fact.'

There is a growing recognition that, when China pushes against US and Asian interests, the latter will push back. This first played out in the East China Sea between 2010 and 2013. Chinese diplomats and analysts questioned US willingness to support Japan in the event of a conflict in the disputed Senkaku/ Diaoyu Islands. President Obama, in Tokyo in April 2014, made it clear that Article V of the security treaty between Japan and the United States extends to the islands. The new 2015 Defense Guidelines speak of 'seamless' defence cooperation from peacetime to contingencies.

Meanwhile, tensions are building in the South China Sea, now the locus of contesting approaches to global rules and norms. This will continue as China continues to build ports, airstrips and install military hardware in areas within its claimed nine-dash line. And the United States is just as firmly 


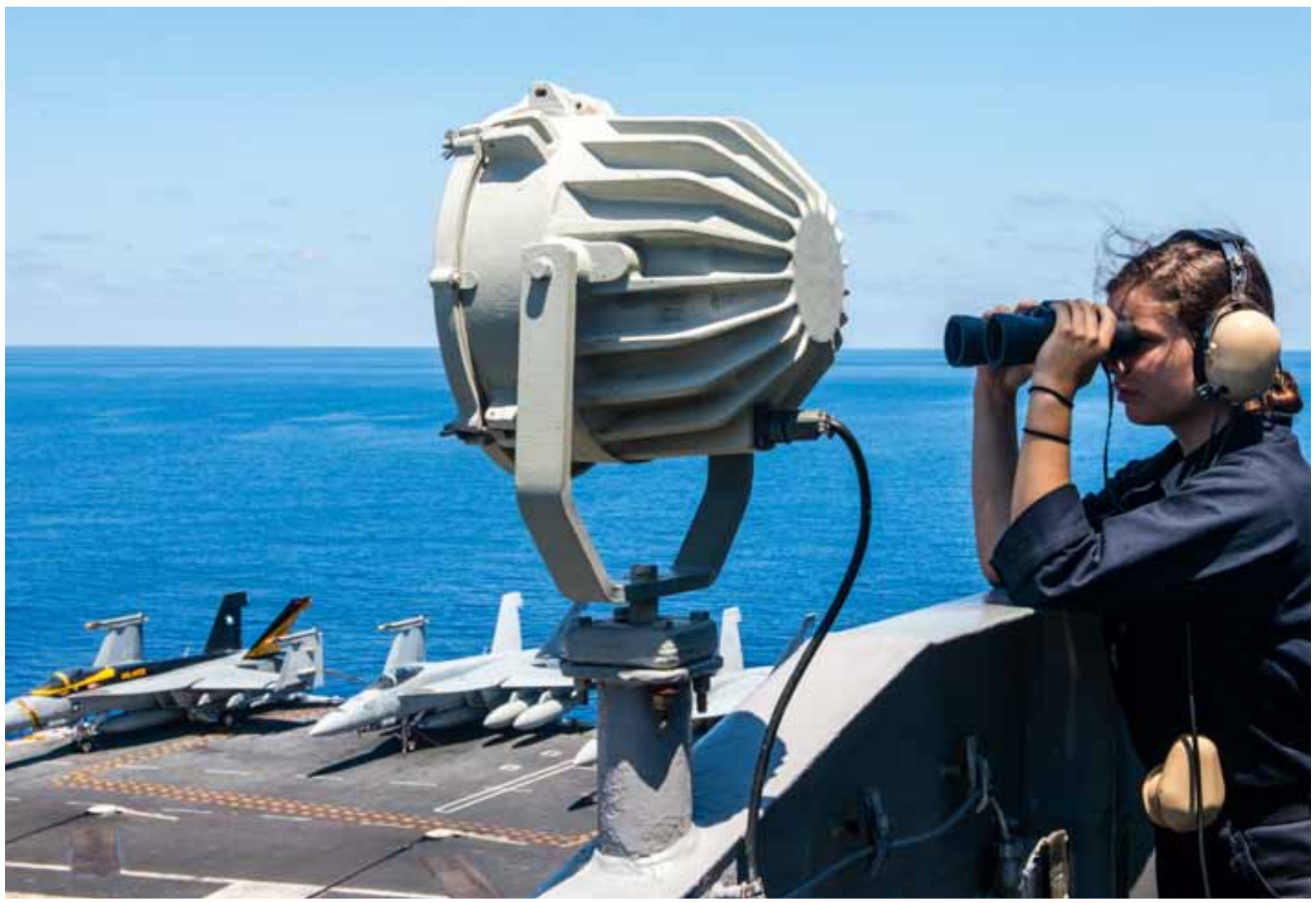

Emma Rolwes, from Marshalltown, lowa, stands lookout watch aboard the US aircraft carrier John C. Stennis in the South China Sea in May 2016. The United States remains 'firmly committed to the principle of freedom of navigation', as its continuing activities in the region demonstrate.

committed to the principle of freedom of navigation, as demonstrated by its growing maritime freedom of navigation exercises. Chinese threats to build new structures on Scarborough Shoal, which it seized from Manila in 2012, may test the US: Will Obama, as he did in regard to the Senkaku/Diaoyu Islands, declare that the US-Philippines defence treaty extends to the disputed territory? And if not, how will Asia perceive that?

Beijing's failure to return phone calls from Hanoi, when Vietnam demanded China withdraw an oil rig from disputed waters, or from President Park in Seoul, after North Korea's missile and nuclear tests, are two recent examples of China's defence mindset. Only when Seoul moved toward US deployment of its Terminal High Altitude Area Defense (THAAD) anti-ballistic missile system did Beijing respond.

When Seoul sought to defend itself from a China-enabled North Korea, China's ambassador in Seoul warned of ominous consequences if THAAD were deployed in the South Korea. The message, as interpreted by an indignant Seoul, was that South Korea should prioritise Chinese security concerns over their own.

What's been driving the evolution of the region's security architecture is a combination of China's efforts to reverse 160 years of humiliation and demand signals from the region that they're not interested in going back to the future.

White's call is for creative alternatives to the current order. So what are these alternatives? Let's start with a 21st century Treaty of Tordesillas. This would divide the Pacific between the United States and China. But where do you draw the line? Would it be an east-west division, or would it run northeast to southwest? Who would get what? Does a democratic South Korea wind up under Chinese suzerainty? Would Taiwan be the price for regional stability?

The 'Congress of Vienna' option, which would formalise a concert of powers, presents similar problems. 
Can the United States, China, Japan, Russia and South Korea agree on a status quo? Are we to expect a resolution of the Taiwan issue and Korean unification? This is doubtful. And where do the lesser actors, like Australia and ASEAN fit in? Do they simply trust the great powers to get it right?

Another potential order is based on the Organization for Security and Cooperation in Europe (OCSE), but for the Asia Pacific region. For US allies, this could be a leap of faith, trading alliance-based security for something toothless. In Europe, OSCE has been a useful adjunct to NATO for purposes like monitoring elections or observing ceasefires. But it lacks any real enforcement power. Will this option be able to resolve South China Sea issues? When push comes to shove, where are the sinews of security?

Finally we have the 'sphere of influence' model. Imagine that under President Trump, the United States issues a proclamation ending all entangling alliances. The United States gets the western hemisphere, China gets Asia and Russia gets

The reality is that the existing alliance structure has provided the region with security for nearly 70 years.

Eastern Europe. How would the region respond? The likely consequences are a nuclear North Korea, a nuclear South Korea and a nuclear Japan. Not exactly a sphere of stability.

None of the above models are particularly appealing for the United States or Asia, and it is difficult to envision a collective security model including both the United States and China. The reality is that the existing alliance structure has provided the region with security for nearly 70 years. It is proving flexible, adapting to meet the challenges posed by an assertive China.

White has a point in that no one has offered a viable answer to the question: for the US, what is an acceptable Chinese role in an Asia Pacific security architecture? Given that the US also has vital strategic interests in East Asia, China needs to answer the question: what is an acceptable US role in the region? Until disputes over Taiwan, the Korean peninsula and the South China Sea are resolved, perhaps the best that can be attained is a framework for strategic stability between the United States and China.

In the meantime, to paraphrase Winston Churchill: the existing security system is the worst possible system-except for all the others.

Robert A. Manning is a Senior Fellow of the Brent Scowcroft Center for International Security at the Atlantic Council and its Strategic Foresight Initiative. His Twitter handle is @RManning4.

James J. Przystup is a Senior Fellow at the National Defense University Institute for National Security Studies (INSS).

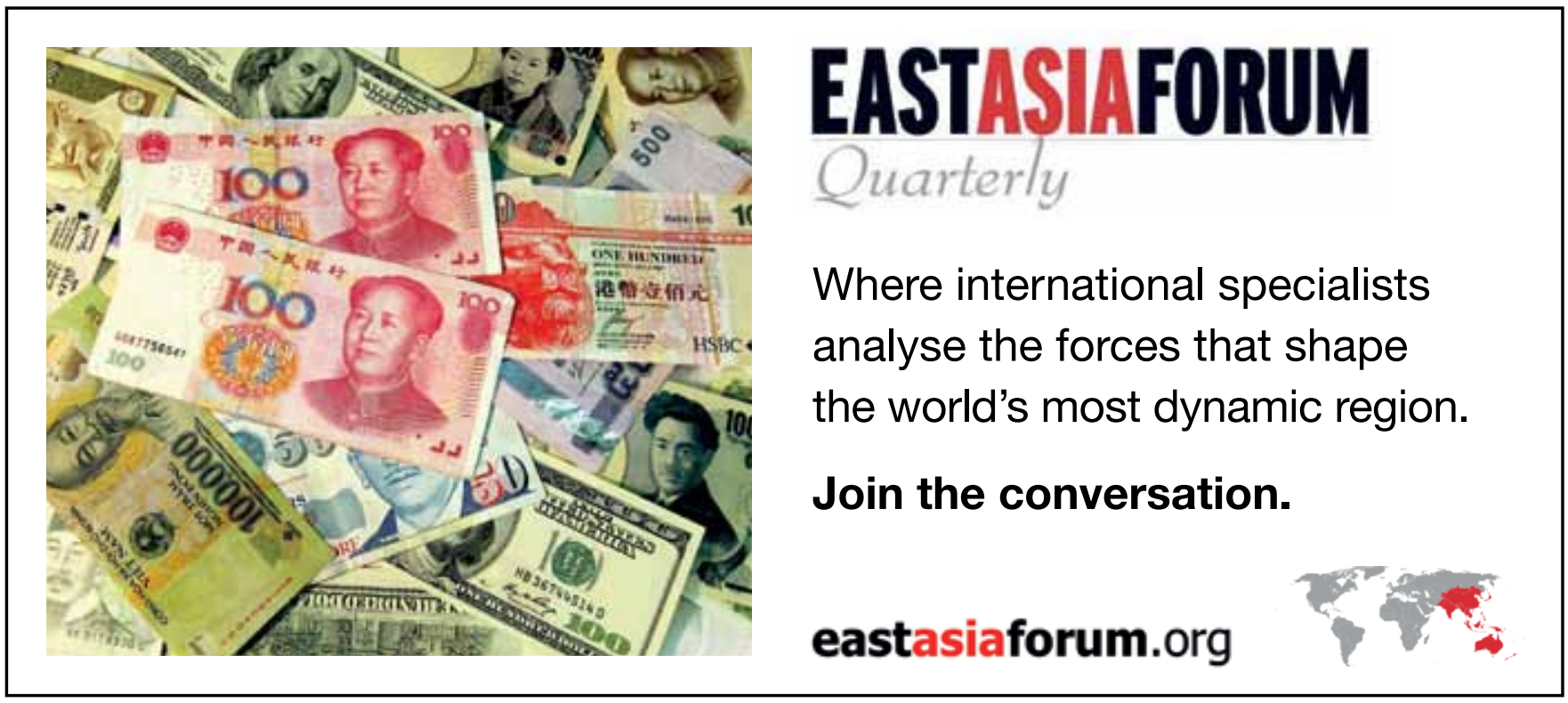




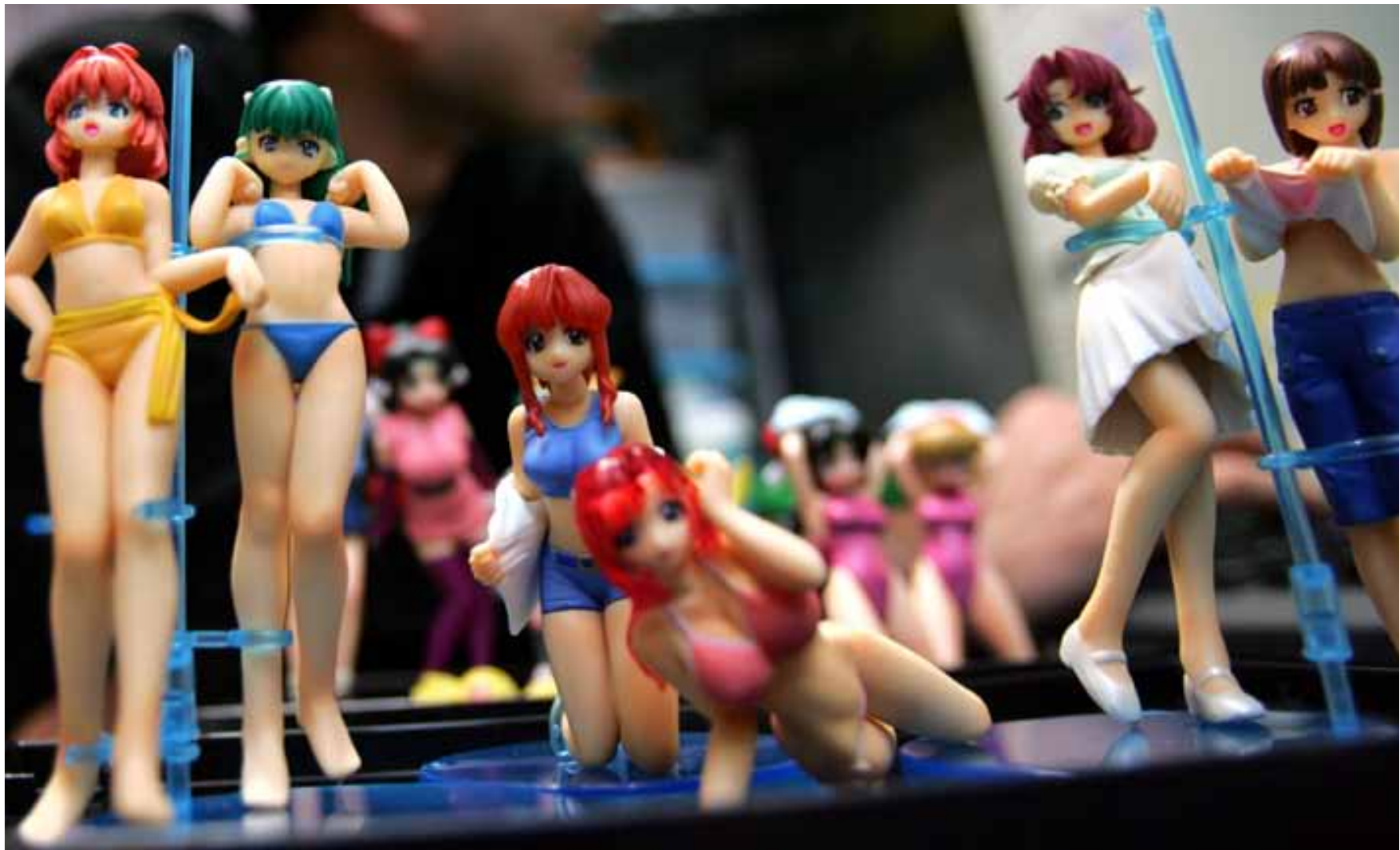

Part of a private collection of anime-faced dolls in Tokyo. A 2005 survey found that a third of male students had seen pornographic manga before the age of 12.

\section{East Asia's pornography trade and abuse of human rights}

\section{CAROLINE NORMA}

$\mathbf{T}$ HE history of the Japanese military's wartime sexual enslavement of women still plays on the mind of East Asia. Japanese leaders make it hard to forget. Most recently, deputy foreign minister Shinsuke Sugiyama told the United Nations Committee on the Elimination of Discrimination Against Women that his government knew of no documents confirming the forcible wartime recruitment of so-called 'comfort women'. The refusal of Japan's leaders to admit legal liability or pay reparation to victims makes military prostitution a continuing backdrop to the diplomatic relations of East Asia.

The refusal to admit to sexual abuse in the past is also mirrored in an ongoing inability to recognise and confront troubling sexual norms and present-day sexual abuse. As Japanese historian Hajime Imanishi says, 'The sexual standards and culture that envelop [Japan] developed over the course of history'.

East Asians continue to be reminded of the history of sexual slavery. Pornographic products produced in Japan and exported to countries in the region today constitute a continuing statement of the sexual 'standards and culture' maintained by some Japanese men, and supported by many other male populations in the region.

Japan's pornography industry emerged in the 1960s. It now releases over 20,000 pornographic films a year, with an annual turnover of US $\$ 2-4$ billion. It is an industry the Tokyo-based NGO Human Rights Now describes as 'almost wholly 
unregulated'. It cultivates a domestic operating environment geared to its commercial activities, with 'junior idol,' 'modelling' and chakuero (non-nude sexualised film) businesses grooming local young women for recruitment.

The industry exerts significant influence on mainstream Japanese society and culture, including among children. For example, a 2005 survey of 10,000 high school students by Asahi Shimbun found that one-third of male students had seen pornographic manga pictures before the age of 12 and nearly 20 per cent had seen a pornographic film. Similar figures for the age group were not recorded in Australia until 2013, well after that population had access to the internet. Today, Jake Adelstein and Angela Erika Kubo see Japanese society as exercising 'surprising tolerance for sexual exploitation of young children as entertainment' and, as a result, 'Japanese "entrepreneurs" at home and abroad are ... major producers of child pornography in the world market'.

Within this world market, the countries of East Asia are particular export targets. International relations scholar Hiro Katsumata writes that 'the spread of Japanese cultural products can be considered an "East Asian" phenomenon'. These products include those of the sex industry, which are produced by pornographers

\section{EASTASIAFORUM renctint}

IN OUR NEXT ISSUE ...

\section{Reinventing Japan}

The violation, torture and degradation of Japanese women and girls that is transmitted to East Asia via pornography exports set a standard for sexual mores in the region

who violate the human rights of local Japanese women and girls, as documented by Tokyo-based groups like the Anti-Pornography and Prostitution Research Group, People Against Pornography and Sexual Violence, Lighthouse and Human Rights Now. This documentation includes the almost unreadable accounts that emerged in the criminal prosecution of employees of one pornographic studio, Bakkii Visual Planning in 2007. In this case a number of men were charged with seriously injuring women in the making of pornography. But even the survivors of the bulk of pornography production that does not reach Japan's courts report serious violations of health and safety, sexual abuse and forced participation in harmful sexual activities. These abovementioned groups now coordinate legal and welfare services for victims fleeing pornographers who use extortion and violence to keep them in the industry.

Products produced on the basis of these kinds of human rights abuses are exported to the countries of East Asia that were subject to the prostitution entrepreneurship of Japanese men. This entrepreneurship included not just military development of so-called 'comfort stations' during wartime, but also pre-war civilian development of legalised brothel districts.

The capacity of pornography to exert transnational cultural influence was first noted in 2006 by feminist theorist Catharine MacKinnon, in relation to US-produced pornography: 'the international pornography traffic means that American women are violated and tortured and exploited through its use ... [and, as a result,] misogyny American style colonizes the world ... [q] ualities characteristic of but not unique to the United States-including common and casual sexual violence and racism ... [are now, through pornography] promoted throughout the world as sex.'

In 2011 Laura Miller noted that the Japanese government's 'Cool Japan' international marketing campaign drew on misogynistic themes. 'When I see the MOFA's [Ministry of Foreign Affairs] version of girls and popular culture', wrote Miller, 'as well as much of Cool Japan as advocated by global otaku, I cannot quite escape the feeling that I endured a stroll through a Kabukicho corridor [Tokyo's largest red-light district] where numerous touts beckon one into an array of sleazy clubs and bars'.

But more than a sexualised image of Japan is being exported abroad. So too is documented evidence of sexual abuse of the country's women and children in the form of pornography. This trade has a long history. By the early 1980s, the Japanese publishing industry was exporting pornographic products to its East Asian neighbours. Japanese pornography found its way to Taiwan in the mid-1980s, when illegal cable TV operators broadcast manipulated Japanese adult videos. In South Korea, in 1980, 28,000 offensive, violent or obscene comic books from 
Japan were confiscated by authorities.

By all accounts, Japanese pornography continues to flow into Taiwan. In 2013, Taiwan's supreme court refused to grant leave to a Japanese pornographer to pursue copyright claims over piracy activities by local Taiwanese pornography distributors, in spite of lost earnings for the company reaching an estimated 1 billion Taiwanese dollars (over US\$30 million). South Korean society, to a lesser extent, now faces the same influx of pornographic material after import bans on Japanese cultural products were fully lifted in 2004. Chyng Sun and colleagues note that pornography production in South Korea is heavily policed, and so most products consumed in the country are 'imported from overseas, primarily from Japan'.

On the Chinese mainland, authorities mostly interdict the internet transmission of pornography into the country, so pornography imported from Japan is not found there in large volume. Yet there is evidence of disk-based Japanese products being illegally smuggled into China via Hong Kong.

The violation, torture and degradation of Japanese women and girls that is transmitted to East Asia via pornography exports set a standard for sexual mores in the region. This standard was similarly instituted within the Greater East Asia Co-Prosperity Sphere during the years of the China and Pacific wars, if through different means.

Knowledgeable commentators around the world now condemn the historical wartime military prostitution system as an institution of female sexual slavery, but the contemporary activities of Japanese pornographers are yet to be similarly judged. While Japanese pornographers are pimping their countrywomen to the men of East Asia in this way, their home-grown pornography acts as an enticement to transnational fraternal complicity in sexual abuse, and therefore silence about gendered crimes in the region's history. EAFO

Dr Caroline Norma is Lecturer in the Master of Translating and Interpreting degree at RMIT University.

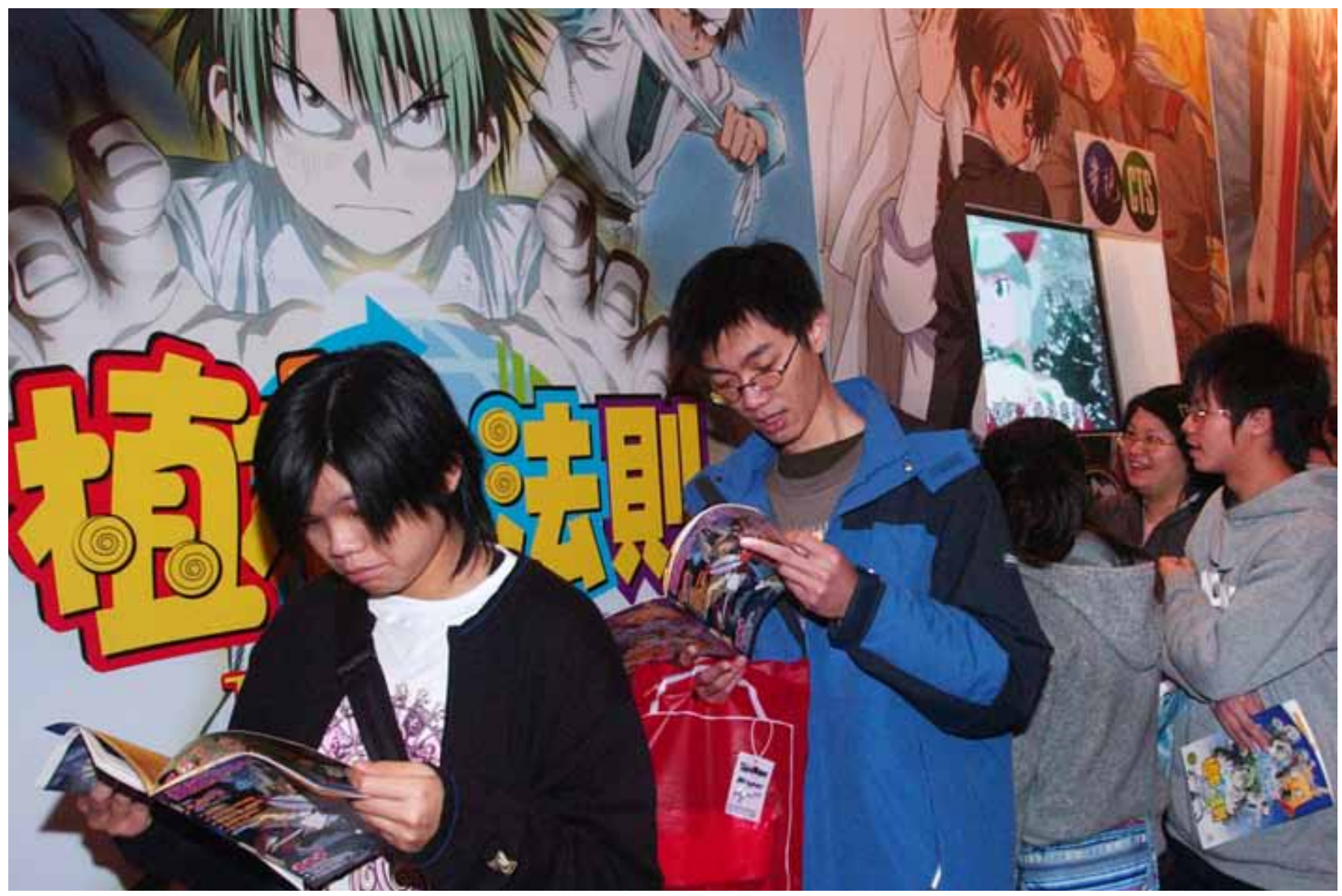

Young Taiwanese leaf through Japanese manga at a book fair in Taipei. International relations scholar Hiro Katsumata says 'the spread of Japanese cultural products can be considered an "East Asian" phenomenon'. 


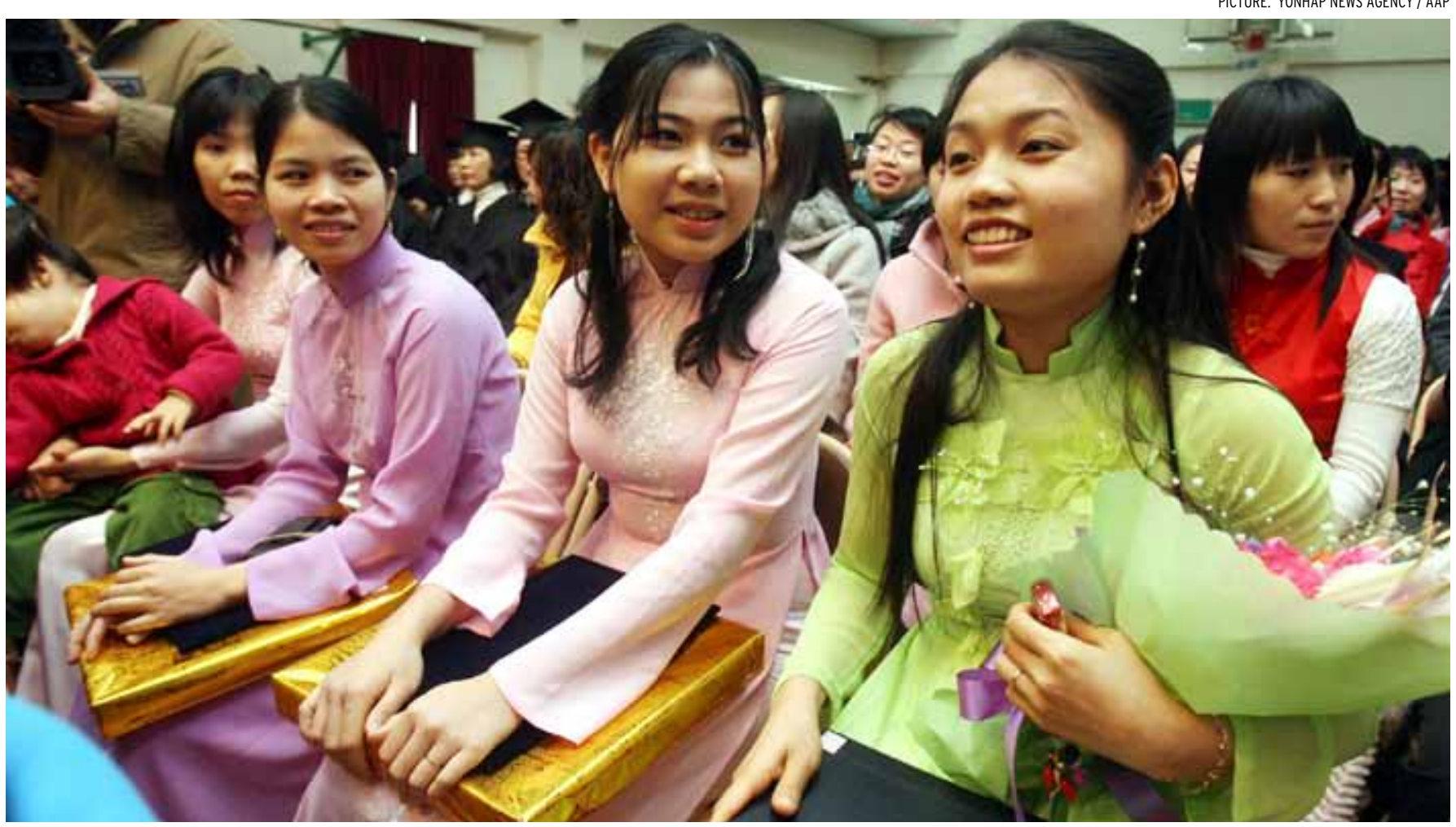

Migrant wives, dressed in the apparel of their native countries, after graduating from a Korean-language course.

\section{The 'strangest others' find a place at home}

\section{HYUN MEE KIM}

$\mathbf{T}$ HE most significant change in inter-Asian migration in recent years has been the shift from male-centred production migration to reproductive migration. Of all migrants in Asia, women represented 42 per cent in 2015. Reproductive migration is voluntary migration to form partnerships, help raise children, or work as nurses or domestic carers. The number of female reproductive migrants in Asia has increased dramatically. This has resulted in the 'feminisation' of migration.

Reproductive and caregiving labour has increasingly become a marketable commodity with concrete value in the global market. This is not only due to the widening economic gap within Asia, which has activated intra-Asian migration parallel to that from Asia to the West. East Asian countries, such as Japan, South Korea, and Singapore, and Taiwan, have successfully sustained economic development, improving well-being through activities including childbearing, childrearing, labour and welfare. However, the recent crisis of social reproduction experienced in these countries has played a significant role in the change.

These nation-states have been facing a demographic crisis of considerable proportion since the 1980s, due to low fertility rates, a rapidly ageing population and a decline in able-bodied workers. Japan, South Korea and Taiwan have each sought to tackle these demographic problems through interventions in marriage and family structures that aim to secure a stable population and build the workforce. Women who enter these countries as marriage migrants are accepted as potential citizens in an effort to restore a balanced ratio in the marriage market, especially for lower-class local men. These women legitimise their claim to citizenship on the basis of their reproductive role as bearers of children. 
It has become increasingly difficult for women in Japan, South Korea and Taiwan to stay at home and perform the traditional household duties of wife and mother within the family. More women have joined the labour force and the size of the ageing population has increased, so many men and married women seek substitutes to perform these duties. These nations have thus turned the rising need for care work into a profitable market niche. Migrant women from less developed Asian countries are recruited to provide reproductive labour. This includes migrant domestic workers and marriage migrants.

W OMEN currently form the majority of foreign residents of Japan, South Korea and Taiwan, representing 53 per cent, 55 per cent and 72 per cent of the foreign resident population, respectively. Social reproduction, which in the past has been largely conducted by the family and the state, is now becoming de-regionalised through inter-Asian gendered migration.

This was mainly due to the significant increase in the tuition fees with the marketisation of education and the lack of welfare benefits to support care for children and the elderly population. These have brought substantial financial burdens on families, and hence have thwarted the expectations for a better quality of life through having a family. People are increasingly likely to postpone marriage and have fewer children.

But these so-called intimate mobilities' into the domestic sphere do not necessarily enhance affective connections of Asian people in terms of cultural contact. Women migrants in these countries, who have come to occupy the most intimate spaces and perform the most intimate functions, are often regarded as the 'strangest others' due to their ethnicities and class status.

The presence of foreign wives, domestic workers and nannies, especially those from Southeast Asia, has often sparked anxiety among the public in the host countries. Northeast Asian societies have traditionally regarded the reproductive sphere of family and marriage as being at the core of their national culture and ethnic identity, but this private domain now faces critical challenges from the growing dependence on foreign women. Chief among these challenges is the question of how to preserve a homogenous ethnic society in the face of the increasingly hybrid culture that has emerged with the reliance on reproductive migration.

Ethnocentric responses to female migration are common in these countries. The discourse on women migrants is strongly racist. It is often based on the idea that foreign women are inferior and their mere presence diminishes the quality of the host society and its people. Policy has emphasised their biological otherness, and their maternity rights are often denied. In Japan, for example, a child born out of wedlock to a foreign woman is given citizenship rights only when a Japanese biological father proclaims his fatherhood of the baby before it is born (that is, when it is still a foetus).

The South Korean government designates families formed out of international marriages as 'multicultural families'. The government has implemented a strongly assimilationist model through a variety of programs designed to quickly 'Koreanise' ethnically different marriage migrants. In Taiwan, anxiety over migrant women and their children has given rise to a racialised discourse that conveys a eugenic attitude of ethnic inferiority. The Singaporean government deports women migrants working as domestic helpers or nannies who become pregnant or give birth while they are in the country.

On the other hand, there have been some positive efforts to accommodate multiculturalism. Since the 1990s, the concept of multiculturalism has been introduced in these countries as a new way to manage the 'differences' that exist between the mainstream majority, ethnic minorities and migrants. 'Multicultural coexistence' in Japanese society, 'multicultural society' in South Korea and 'multiculturalism' in Taiwan have been adopted in social discourse to promote coexistence of locals and foreigners.

\section{A} LTHOUGH there is increased acceptance of multicultural realities and lifestyles, the shift from a mono-ethnic ideology to a multicultural society has triggered a rise in jingoistic rhetoric and antiforeigner sentiment. The discourse of aversion and suspicion around foreign migrants on the internet and social media are ample evidence that deep-seated views of what it is to be Japanese, Korean or Taiwanese have yet to substantively change.

Despite controversies over the term 'multiculturalism', new social accommodations have yet to reduce inequalities in power among diverse groups, especially 'women migrants at home.' The problems of equality, gender rights and citizenship are not fully addressed in the age of of high female migration in East Asia. EAFQ

Hyun Mee Kim is Professor in the Department of Cultural Anthropology, Yonsei University, South Korea. 


\section{Japan's military battles its own male-dominated culture}

\section{SABINE FRÜHSTÜCK}

$\mathbf{0}$ N 4 November 2014, LieutenantColonel Chizu Kurita of the Japan Ground Self-Defense Force became the first Japanese military officer to be attached to NATO headquarters in Brussels. As advisor to the NATO Special Representative for Women, Peace and Security in the office of the Secretary General, she has been primarily advising the body on the how to better integrate a 'gender perspective' into its policies and activities.

Kurita's role in Brussels is a politically important gesture, but it also draws attention to the troubled condition of gender integrationor 'gender mainstreaming', as the Japanese administration puts it-in the Japanese Self-Defense Forces (SDF). Tellingly, Kurita herself is one of only a handful of high-ranking female officers.

Between 1986 and 1993 almost all branches of the SDF opened their doors to female recruits. By the year 2000, most restrictions for women had been formally lifted. The SDF's most significant remaining barrier to gender integration-its overwhelmingly male military culture-had also been targeted so as to 'modernise' the institution, which could then promote itself as providing greater gender equality than corporate Japan.

That self-promotion was articulated in such policy documents as the Ministry of Defense's multi-year Basic Plan for Gender Equality, released in
2011, and subsequently implemented in the context of the gender equality policies pursued by the administration of Prime Minister Shinzo Abe. For its part, the Ministry of Foreign Affairs' new National Action Plan on Women, Peace and Security highlighted how SDF personnel were being provided with training on gender issues, sexual violence and 'women's care needs' before their deployments.

But although the administration of Prime Minister Shinzo Abe has widely publicised its efforts to advance gender equality throughout the public sector, the Ministry of Defense (MOD) goals for 2016 and beyond remain modest. Japan's 2015 defence white paper sets

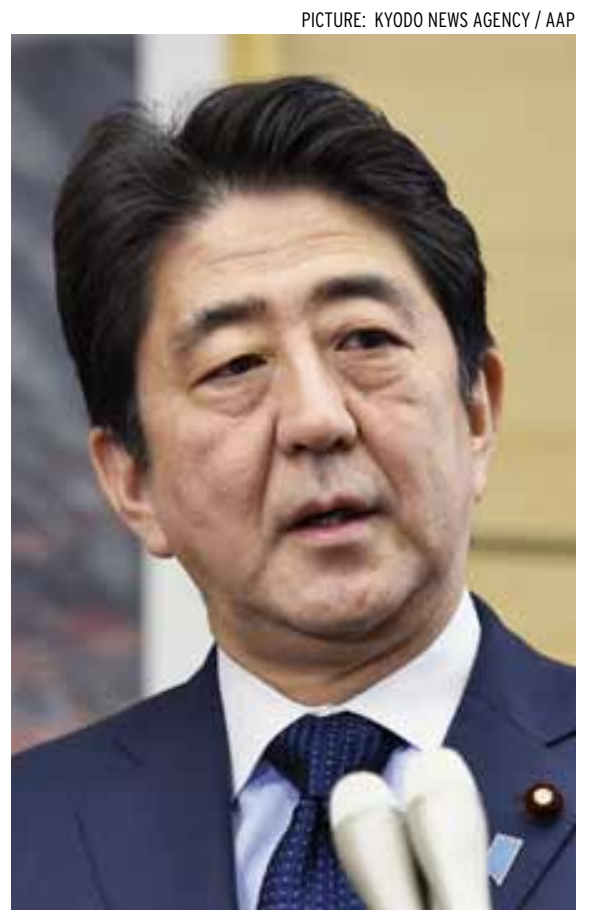

Prime Minister Shinzo Abe, whose administration has launched several plans for gender equality. a goal that from 2016, 30 per cent of all new MOD staff should be female, but it makes no concrete target for uniformed SDF personnel beyond a commitment to increase the female proportion of new recruits from its current level of 7.6 per cent.

Many women are motivated to join the SDF to liberate themselves from the gender and class restrictions of their predominantly rural, working class or lower middle class communities. Their decision often faces opposition from family members who are concerned as much about the recruit's safety as their prospects for having a family of their own down the line. Since being a service member calls for the willingness to move on to a new base every two or three years, some female recruits perceive geographical mobility as their only shot at the social mobility they desire.

Not surprisingly, gender equality is a concern for potential female recruits. A considerable number of women who join the SDF do so with two expectations: that they will be advanced on the basis of their performance, and that they will be treated as equals to their male colleagues. The defence white paper for 2015 does report significant advances for female uniformed SDF personnel. Their numbers have increased at SDF staff offices and headquarters. Some female members now board escort vessels and pilot both antisubmarine patrol aircraft and transport aircraft.

Yet significant restrictions based 
on maternity and privacy concerns still exclude women from specific assignments to tanks, submarines and fighters. As a result, in the past 20 years, the percentage of women in the SDF has risen only minimally, from just under 5 per cent in the mid-1990s to 5.6 per cent today-about 13,000 service members out of a total of 232,143.

Why has the gender composition of the defence and security apparatus changed so little? For one thing, while the SDF invests heavily in the gender management of its public image, the ideal it publicises does not match its reality.

For example, SDF public relations materials eagerly feature female service members-attending to victims of natural disasters, playing with or performing for children, or simply smiling prettily while saluting in uniform-far more prominently than their numbers justify. Ultimately, the welcome that new female recruits believe they will receive does not last long.

Outdated ideas about war being only the realm of men persist in the military. Though engaging in female-exclusionary practices is constitutionally prohibited, many male service members at all levels and ranks actively resist the integration of women, who then feel isolated and marginalised. As a result, female service members lack opportunities for the tactical and strategic-level planning and decision-making experiences that are crucial for career advancement. The numbers say it all: only 2.8 per cent of current field officers or higher are female, there is only a handful of female colonels and there are no female generals.

In many ways this situation simply reflects the state of gender affairs in civilian society, where career paths and

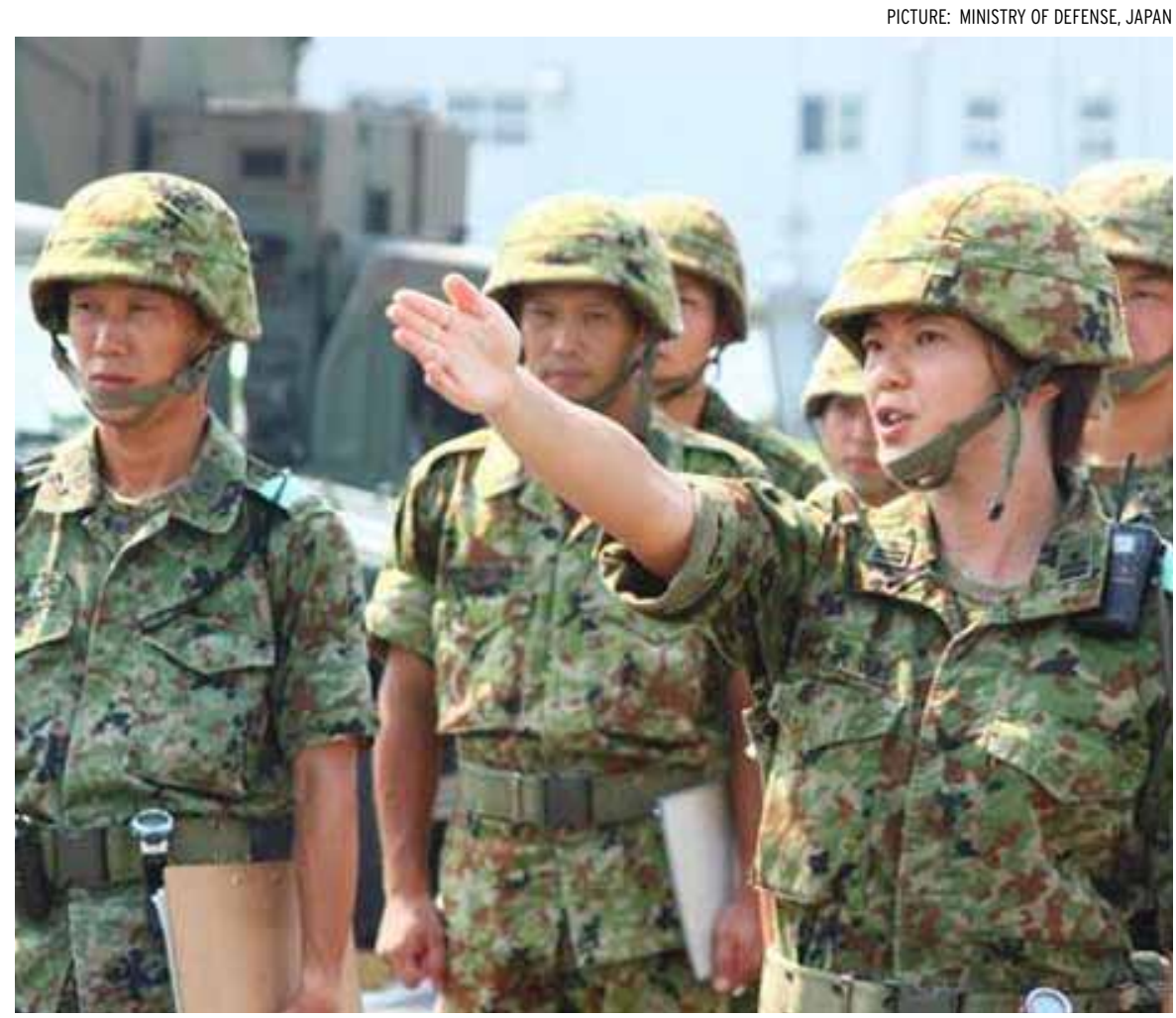

Lieutenant-Colonel Chizu Kurita giving directions to a squad. Though her appointment to Brussels as advisor to the NATO Special Representative for Women, Peace and Security is 'a politically important gesture', she is one of only a handful of high-ranking women officers in the Japanese services.

managerial positions also continue to be overwhelmingly occupied by men. But a different reality looms on the horizon, resulting from two significant factors. One is that the forces have endured a recruitment shortage of men for decades that only worsened

... significant restrictions

based on maternity and

privacy concerns still

exclude women from

specific assignments to

tanks, submarines and

fighters when Prime Minister Abe claimed Japan's right of collective self-defence in July 2014.

The other is demographics. Japan's low fertility rate-widely believed to be the result of young women's resistance to traditional life paths that largely exclude them from serious careerswill further exacerbate the decline in numbers of young men eligible for military service.

These factors will likely lend a greater sense of urgency to efforts to further integrate and advance women in the defence and security complex.

\section{EAFQ}
Sabine Frühstück is Professor of Modern Japanese Cultural Studies in the Department of East Asian Languages \& Cultural Studies, University of California at Santa Barbara. 


\section{Women's image transformed: femininity in North Korea}

\section{BRONWEN DALTON AND KYUNGJA JUNG}

MPORTANT changes are taking place inside North

Korea. The collapse of the command economy, and the emergence of capitalism in its place, is ongoing. A burgeoning moneyed elite and increasing exposure to foreign pop culture are transforming how North Korean femininity is conceived. These changes are reaching far beyond Pyongyang to affect many, if not most, women in the country.

Officially, North Korea's founding juche (selfreliance) ideology supports gender equality. In practice the leadership cult that was entrenched under Kim Il-sung, who led the country from 1948 to 1994, gave patriarchal relations a significant boost. Under Kim Il-sung, the nation was recast in line with traditional, largely Confucian, male-dominated family structures-a considerable backslide from the progressive gender norms promoted by the early Korean socialist movement. Despite its rhetoric, Kim Il-sung's juche ideology directly perpetuated gender subordination.

To this end, North Korea's leaders were active in controlling women's behaviour and appearance to ensure alignment with state prescribed ideals of femininity. For decades the embodiment of the feminine ideal was Kim Ilsung's mother, Kang Ban-sok. Kang, who is eulogised as a passionate revolutionary fighter and leader of the Korean women's liberation movement, is referred to as 'the Great Mother of Korea'.

Unlike other socialist regimes that embraced masculine clothing as a symbol of revolutionised women, Kang Ban-sok consistently appears in state iconography in native Korean dress and with a traditional hairstyle. This depiction served to reinforce femininity as tied to a traditional, subservient, 'purely Korean' selfless mother. Sonia Ryang, Director of the Chao Center for Asian Studies at Rice University, argues that this interpretation of women was so dominant that while "the category "mother" exists in North Korea, the category "women" is hardly recognised, thereby effacing the notion of gender altogether from the surface of the state politics'.

Under Kim Il-sung and Kim Jong-il authorities sought

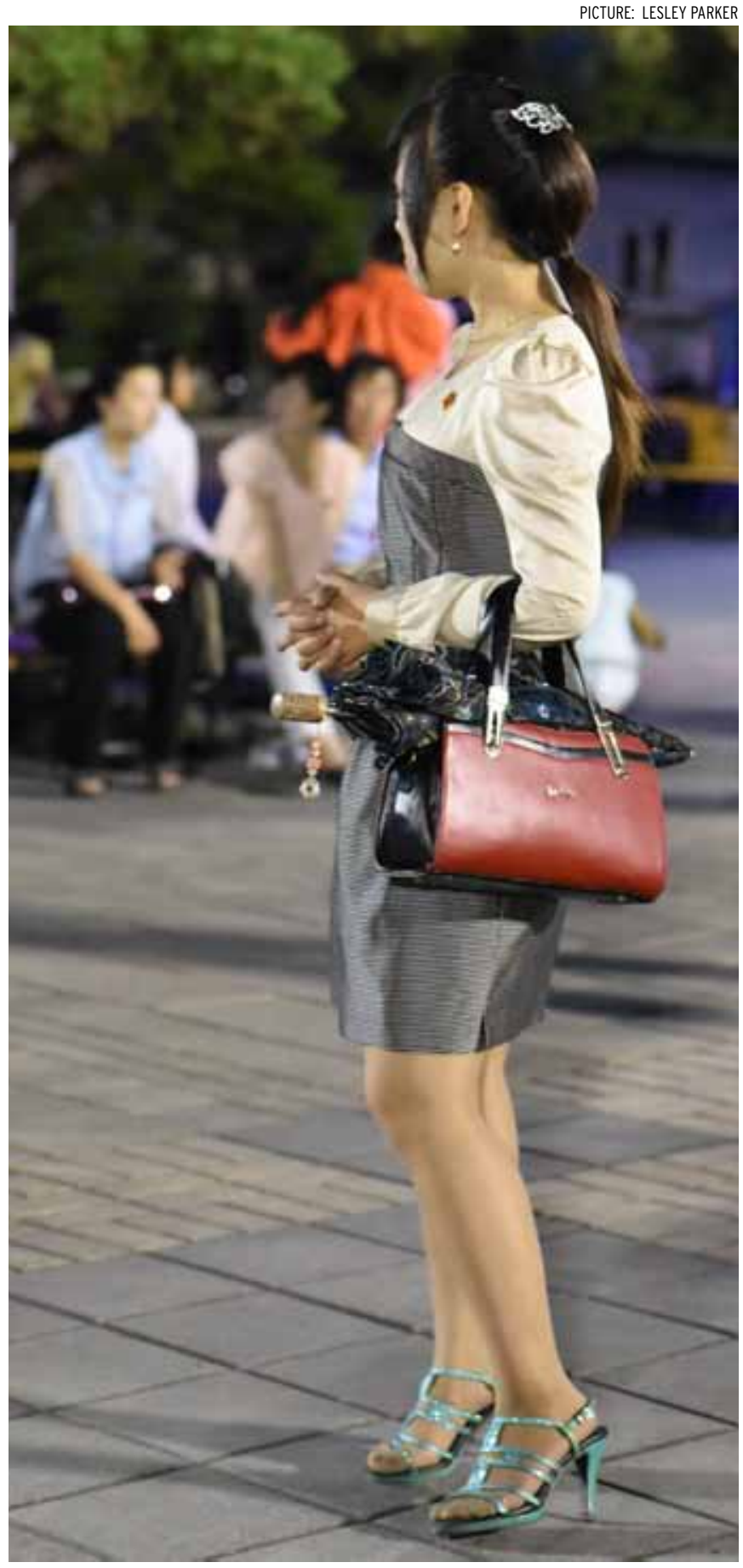

A stylish young woman strolling in the streets of Pyongyang. 'Capitalist' hyper-femininity is evident in all of North Korea's major cities. 
to reinforce this ideal by controlling women. Policing women's dress and suppressing the wearing of trousers, blue jeans and earrings, for example, were part of a range of official attempts to eradicate Western culture that could potentially corrupt the purity of North Korean women.

The famine of the mid-1990s, during which hundreds of thousandsand perhaps as many as two millionNorth Koreans died, challenged this status quo. Largely in an effort to ensure that they and their families survived, North Korean women took a leading role in establishing an emerging market economy.

Ongoing female participation in the market and, in particular, their new role as family breadwinners, afforded North Korean women many new opportunities, including a modicum of economic power. This relation is reflected in the common usage of expressions such as 'a man's only use is to be a lock to secure the house', or to be 'a guard dog that stays at home all day', or 'a light bulb during the day'.

There is some evidence that a preference for sons has diminished, with parents seeing women as more likely to reap benefits in the emerging economy. But recent developments in the social construction of femininity suggest that the relationship between market participation and female empowerment is complex. Perhaps ironically, the North Korean form of capitalism that women have helped to create is likely to frustrate any substantial change in gender relations.

North Korean capitalism has continued apace under the benign neglect-and tacit encouragement-of Kim Jong-un. Now North Korea is undergoing a transition from a society where status is prescribed by the state to one where social status is tied to success in the market.
In this increasingly materialistic and consumerist society, Kim Jong-un's wife, Ri Sol-ju, has become a visible and influential trendsetter. North Korea's state news agency has featured $\mathrm{Ri}$ at various public events wearing high heels and form-fitting, stylish clothes. She has even been spotted sporting a variety of designer brooches in place of the 'dual portrait' lapel pin, which carries the images of former leaders Kim Il-sung and Kim Jong-il. Other North Korean fashion icons include the women in the country's most popular girl band, Moranbong. Their short skirts, high heels and sequined outfits have inspired or reinforced the trend among women to wear brighter, better-cut clothing.

Now social status is becoming more closely

\section{connected to financial}

\section{success}

Today, many North Korean women prefer logo-emblazoned goods, as well as anything that can incorporate sequins or diamantes-tops, hairpins and even high heels. The latter, especially, have become de rigueur.

In Pyongyang the wives, daughters and mistresses of the new rich, or donju ('masters of money'), are immaculately turned out. Unlike other symbols of wealth, such as fridges or air conditioners, being accompanied by a fashionable female is a conspicuous way of displaying wealth.

This 'capitalist' hyper-femininity is evident in all of North Korea's major cities. There are reports of tailors across North Korea producing a huge range of counterfeit designer clothing. Cosmetic surgery is performed throughout the country and local markets do a brisk trade in earrings, handbags, clothing and make-up from China and South Korea.

But market participation and fashionable clothing do not indicate a more liberal order or any substantial empowerment of women. North Korea remains a heavily state-controlled and patriarchal country.

Despite running most of the stalls at local markets, North Korean women have nowhere near the same opportunities as men in terms of careers and money-making. In this context, dressing extravagantly could be seen as a normalised, tactical approach for women aspiring to secure a good career, marriage or even a boyfriend. Women may prefer conspicuous consumption that signals status to others.

Under juche ideology, women's bodies were regulated and controlled by North Korean authorities. The aim was to meet a set of ideals closely aligned to the traditional role of the woman as producer, reproducer and child rearer. Now social status is becoming more closely connected to financial success. Women increasingly embody the markers of status and wealth through the conspicuous consumption of material goods, thus playing a key role in modern status reproduction. As North Korea changes, a new femininity has begun to emerge.

Bronwen Dalton is the Director of the Masters of Not-for-Profit and Community Management Program at the University of Technology, Sydney.

Kyungja Jung is Senior Lecturer in the Social and Political Sciences at the University of Technology, Sydney. 


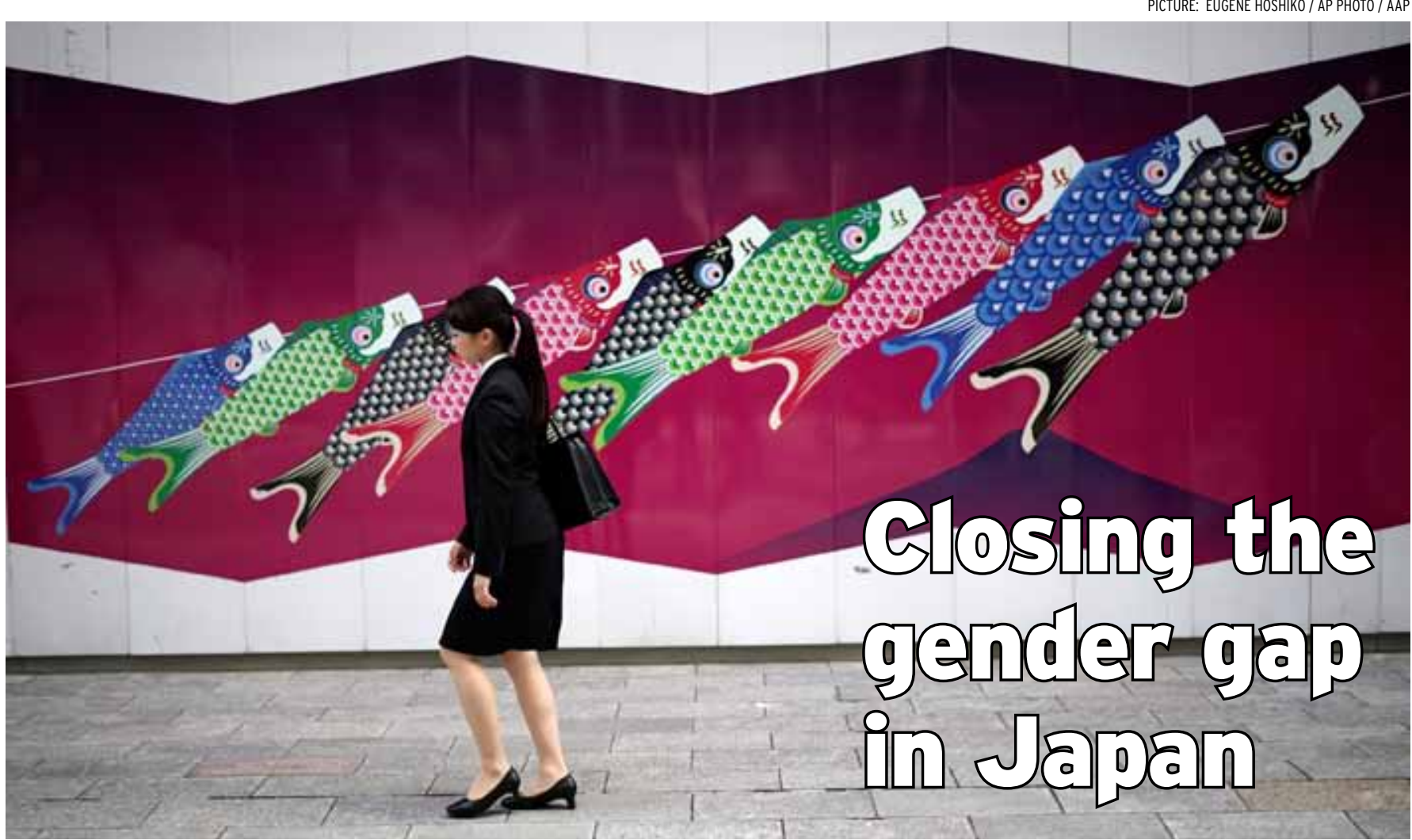

VERA MACKIE

W OMEN in Japan voted and stood for office for the first time on 10 April 1946. It was the country's first postwar election and the first election after the Japanese government amended the Electoral Law to include women. Of the 79 female candidates, 39 were elected to Japan's national parliament, the Diet.

Seventy years on, what is the state of gender relations in Japan? What issues now stimulate feminist campaigns and activism?

The most recent Global Gender Gap Report, which_measures the gaps between men and women in each society, ranked Japan 101st out of the 145 countries surveyed. Of the report's four subindices, Japan ranked 106th in women's economic participation and opportunity, 84th in educational attainment, 42nd in health and survival and 104th in political empowerment.

Japan has almost closed the gender gap in education and in health, but much more has to be done in terms of economic and political participation.

Japan now ranks equal 157th of 191 countries in women's political participation according to the International Parliamentary Union. After the 2014 election, 45 out of 475 lower house members were women (9.5 per cent) and after the 2013 election, 38 of 242 upper house members were women (15.7 per cent). In 2015, 22 per cent of ministerial positions in Japan were held by women, but only 25 individual women have served in Cabinet in the whole postwar period.

As for work, for much of the postwar period, women's labour-force participation has been characterised by an M-shaped curve, whereby women leave the workforce on the birth of their children and return, often part-time, when their children reach school age. Although the curve is becoming shallower, there remains a significant gap between the number of women working and the number of women wishing to work.

The female employment rate is 63.6 per cent, compared with around 95 per cent for men, with women more likely to be found in non-regular employment. Some 43.9 per cent of women leave work on childbirth. These figures reflect the continued difficulty in reconciling paid work with domestic work, as has been pointed out by feminist critics since the mid20th century.

Much progress on gender policy in Japan was made in the 1990s. In line with the recommendations of the Beijing Platform for Action, which came out of the 1995 United Nations World Conference for Women, gender issues became a central policy priority. The late 1990s saw the passing of the 
Basic Law for a Gender Equal Society, the Plan for a Gender Equal Society and the creation of the Office for Gender Equality, now in the Cabinet Office.

This growing feminist influence on gender policy was met by a conservative backlash, led by current Prime Minister Shinzo Abe of the Liberal Democratic Party (LDP), in the early 2000s. As part of the LDP's project team for 'Investigating the Status of Radical Sex Education and Gender Free Education', Abe and his allies attacked various initiatives that they saw as detrimental to what they called 'traditional' cultural values. This prompted media panics about such issues as sex education in schools.

Since his return to office in 2012, Abe has sought a more progressive image on gender issues. A range of policies, such as increasing the number of available childcare places, have been proposed under the slogan 'womenomics'.

International legitimacy, as much as domestic policy, is a guiding objective behind the slogan-as Abe's 2013 womenomics speech at the United Nations indicated. 'I have been working to change Japan's domestic structures', he announced. 'However, this is not confined merely to domestic matters ... this is also a thread guiding Japan's diplomacy'.

C ONTRARY to the stated goals of womenomics, Abe's government recently made it easier for employers in Japan to exploit temporary workers-a group which is disproportionately female-on long-term contracts, removing earlier restrictions.

Another controversial policy encourages the use of immigrant domestic workers in speciallydesignated economic zones, in order to improve women's labour participation. This policy has been criticised for entrenching the idea that housework and childcare are women's responsibilities. It leaves intact a work culture that makes it difficult for full-time employees to take part in childcare and domestic labour and achieve work-life balance.

It is likely that only elite professionals would be able to afford such assistance. This policy will do little to assist the large numbers of women who still leave work on the birth of their children and can only find part-time work when they return to the workplace. It would also entrench regional inequalities as those from poorer nations travel to richer nations to engage in domestic work and care work. Policies on gender relations need to be seen in a transnational and regional frame.

The 'baby-boomer' generation of feminists who led the women's liberation movement of the early 1970s and the reformist feminist groups of the 1970s and 1980s are now at retirement age. They must be experiencing a sense of déjà vu, as the issues of work-life balance that they raised in the 1970s are still being debated and seem far from being resolved. This cohort of baby-boomers is also dealing with the issues of Japan's ageing society. Many face their own retirement while dealing with their own ageing family members' need for care.

Issues of work-life balance and the gendered dimensions of the ageing society appear prominently in recent editions of feminist magazines and the websites of NGOs. A recent seminar held by the Women's Action Network (WAN) was aligned with international campaigns on 'decent work. The WAN website brought these issues to life with the testimony of a working mother. 'What I finally realised', she wrote, 'is that I should never hand over to the next generation the difficult working and living conditions I experienced as a working mother ... we must change them.'

The history of the Asia Pacific war continues to be a matter of debate in feminist circles, seven decades on. At the end of 2015 the governments of Japan and South Korea attempted a bilateral resolution on the issue of wartime military sexual slavery. The agreement proposed that the Japanese government would provide support to the elderly survivors through a fund to be administered by the South Korean government.

$\mathbf{T}$ HIS attempted resolution was roundly criticised, not least by the survivors themselves. The two governments had failed to consult survivors, the major stakeholders, thereby displaying ignorance of the principles of restorative justice. The agreement also failed to include survivors from countries other than South Korea. It is thanks to transnational feminist activismbringing together networks of activists from throughout Asia and the Pacific - that this issue has stayed at the forefront of international attention seven decades after the war.

Nearly three years on from Abe's womenomics speech, this flawed bilateral agreement reveals the need for more thorough integration of feminist perspectives not only in Japan's domestic policies but also in its international relations. EAFQ

Vera Mackie is Senior Professor of Asian Studies and Associate Dean, Research, in the Faculty of Law, Humanities and the Arts at the University of Wollongong. 


\section{LOOKING FOR LEADERSHIP}

\section{Women and politics in East Asia}

\section{KATHARINE H. S. MOON}

$\mathbf{T}$ HIS is supposed to be the Asian century, with East Asian countries leading the way. The world admires many East Asian countries for their miraculous economic growth, democracy-building and cultural innovation. But can East Asia also provide a model for developing women's rights and political power? East Asia has no coherent pattern to boast or export.

East Asians are known for creating wealth nationally and personally but this does not necessarily produce women's political empowerment or participation. One of the poorest countries in the world, Rwanda, sits atop the very wealthy Nordic states, the United States and newly rich Asia with the highest female representation in national politics worldwide.

In East Asia, the Philippines boasts the highest representation of women in political institutions. Nearly 30 per cent of the Philippines' lower house is occupied by women, and women form a quarter of the upper house. In local politics, women also fare well, with 17 out of 80 provinces having voted for female governors in 2013. Since 2010, women have also made up 40-45 per cent of the highest civil service positions.

Of all East Asian societies, the Philippines is the most advanced in integrating women's rights and development through legal codes and administrative practices. For example, the Local Government Code of 1991 deepened democratisation by decentralising power and by requiring all local and provincial governments to include women, and other underrepresented groups, in governance.

Japan, the wealthiest country in the region, falls far behind, with women holding only 11.5 per cent of nationally elected offices as of April 2016 and a mere 3 per cent of the senior-level positions in central government ministries and agencies as of early 2014. Yet in the last two national elections (2013 and 2014), women made up about 53 per cent of the voters.

This is puzzling, given that Japan is the most developed democracy in East Asia in addition to offering a relatively high quality of life. No doubt Japanese government institutions and cultural norms in political life are unfriendly, if not hostile, to women. But that goes for many other East Asian societies that have nonetheless produced significant numbers of female political leaders in government and civil society. Marriage and children have also become less and less popular, but Japanese women who choose work or careers have tended to avoid politics. Neither Japan nor the Philippines has a quota for female representation in national politics, but Japan ranks lower than the Philippines, China and North Korea.

South Korea does have an electoral quota system, which requires political parties to include at least 30 per cent of female candidates in their district nominations and 50 per cent of appointed proportional representatives. South Korea's National Assembly election of April 2016 yielded 49 female members, or 17 per cent of available elected seats-a record high.

Since 1996 a similar 30 per cent quota has existed for civil service positions. As the number of women in civil service positions grew, the government also set a 30 per cent quota for men in 2003 to combat fears that men were getting 'left behind'. Despite this, only 4.5 per cent of high-level government positions are occupied by women, although this number should grow as women in entry-level positions climb the ranks. As The New York Times reported in 2010, '47 per cent of those who passed the state examination that selects midlevel officials to be groomed for senior posts in agencies other than the Foreign Ministry were women. In 1992 it was 3.2 per cent.'

\section{- OUTH Korean women have - also made the most gains in the} diplomatic corps. In the 2010s about 60 per cent of those who passed the entrance exam were women. This is a stunning leap from just 1.1 per cent in the 1980s, 7.7 per cent in the 1990s and 47 per cent in the 2000s. In 2008, 'the passing rate of women outstripped that of men by two to one.' Merit-based entry requirements are regarded as fairer in democratic South Korea than they were during the country's period of military 


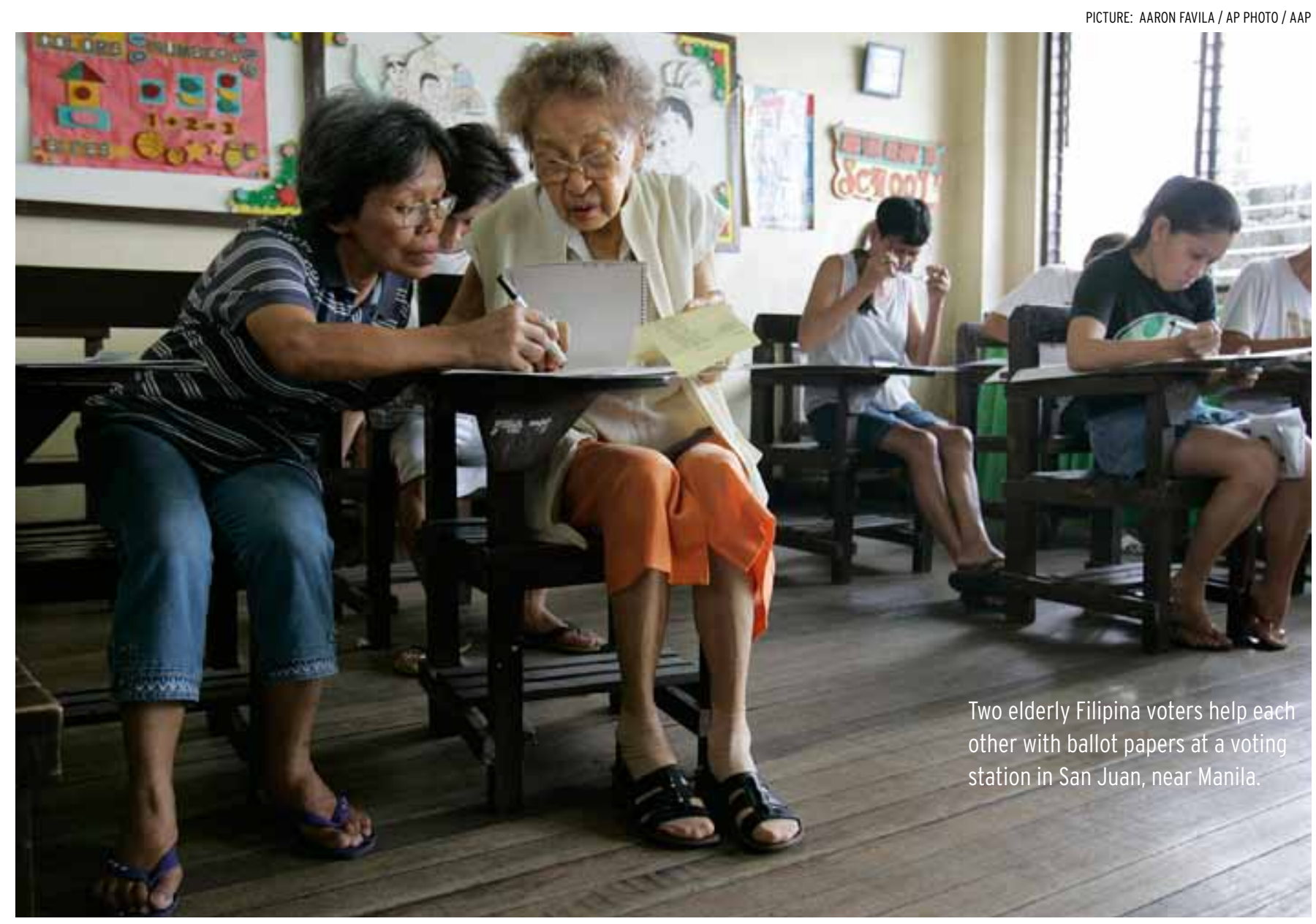

authoritarianism. This might help explain why in Thailand the number of female parliamentarians dropped after the military coup of 2014, from 16 per cent to 6.1 per cent.

China defies conventional logic. Despite decades of communist indoctrination and legal changes that reversed thousands of years of sanctioned male privilege, contemporary China is rolling back women's rights and political participation. Women form small minorities at all levels of the political system: 21 per cent of the Chinese Communist Party and 23 per cent of national civil service jobs. About 1 per cent of village committee chairs, which most directly relate to people's everyday lives, are women. A woman has never been selected for the
Standing Committee of the Politburo, the top governing body. Since 2013 two women have occupied seats in the 25-member Politburo, the first time since the early 1970s.

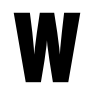

OMEN'S property rights are also less secure now, when more women have money, than they were in the 1950s. In 2011, China's Supreme People's Court interpreted the revolutionary 1950 Marriage Law and its amendments, which granted numerous freedoms and rights including common marital property, in favour of men. Now, marital property essentially belongs to the person whose name is on the property deed.

As Leta Hong Fincher reports, in the top real estate markets of Beijing, Shanghai, Guangzhou and
Shenzhen, 'only 30 per cent of marital home deeds include the woman's name, even though over 70 per cent of women contribute to the marital home purchase.' Given that real estate is a major source of new wealth for Chinese, women are in a losing game.

Despite admirable progress, there is a long way to go yet. While East Asia, with China at the centre, may be on the rise, it still lags behind in terms of women's rights and political representation. EAFQ

Dr Katharine H.S. Moon is Professor of Political Science at Wellesley College and SK-Korea Foundation Chair of Korea Studies and Senior Fellow at the Brookings Institution. 

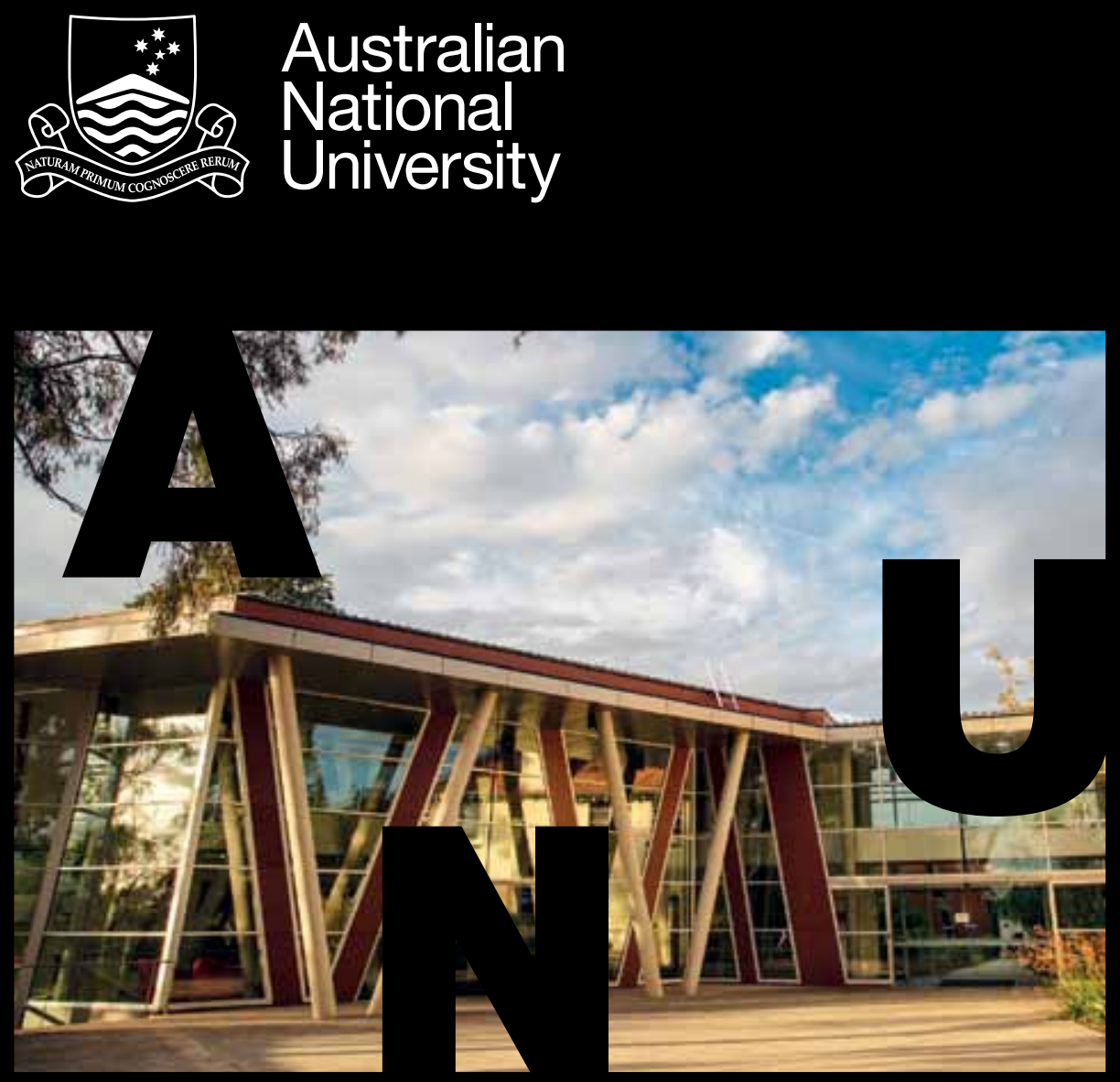

\section{JOIN THE PUBLIC POLICY THOUGHT LEADERS}

$\begin{array}{ll}\begin{array}{l}\text { ANU Crawford School } \\ \text { of Public Policy is }\end{array} & \begin{array}{l}\text { Crawford School staff and } \\ \text { visitors are active on government } \\ \text { renowned for world-class } \\ \text { research, education }\end{array} \\ \begin{array}{l}\text { coles across government, } \\ \text { and policy engagement, } \\ \text { leading and shaping }\end{array} & \begin{array}{l}\text { Join our vibrant policy community, } \\ \text { which brings together scholars, }\end{array} \\ \text { policy thinking in Australia, } & \text { students, policy-leaders and } \\ \text { Asia and the Pacific. } & \begin{array}{l}\text { policy practitioners from the } \\ \text { public, private and NGO } \\ \text { sectors in Australia, the region } \\ \text { and globally. }\end{array}\end{array}$

Explore your options for research partnership, postgraduate study and executive education in the following:

$>$ Public policy

$>$ Public administration

$>$ Applied economics

$>$ International development

$>$ Environmental and resources management, and

$>$ National security. 